\title{
Review
}

\section{Translational medicine of the glutamate AMPA receptor}

\author{
By Tomoyuki MiYAzAKI, ${ }^{* 1, \#}$ Hiroki ABE, ${ }^{* 1, \#}$ Hiroyuki UCHIDA ${ }^{* 2, \#}$ and Takuya TAKAHAshi*1,†
}

(Edited by Shigetada NAKANISHI, M.J.A.)

\begin{abstract}
Psychiatric and neurological disorders severely hamper patient's quality of life. Despite their high unmet needs, the development of diagnostics and therapeutics has only made slow progress. This is due to limited evidence on the biological basis of these disorders in humans. Synapses are essential structural units of neurotransmission, and neuropsychiatric disorders are considered as "synapse diseases". Thus, a translational approach with synaptic physiology is crucial to tackle these disorders. Among a variety of synapses, excitatory glutamatergic synapses play central roles in neuronal functions. The glutamate $\alpha$-amino-3-hydroxy-5-methyl-4-isoxazole propionic acid receptor (AMPAR) is a principal component of glutamatergic neurotransmission; therefore, it is considered to be a promising translational target. Here, we review the limitations of current diagnostics and therapeutics of neuropsychiatric disorders and advocate the urgent need for the promotion of translational medicine based on the synaptic physiology of AMPAR. Furthermore, we introduce our recent translational approach to these disorders by targeting at AMPARs.
\end{abstract}

Keywords: AMPA receptor, synapse, synaptic plasticity, translational medicine, ednonerpic maleate, PET probe

\section{Introduction}

Over 100 billion neurons constitute the adult human brain. Within the brain, the synapse is the structural unit used to convey information from one neuron to other neurons. Upon propagation of electrical excitation, called an action potential, to a presynaptic terminal, chemical neurotransmitters stored in the presynaptic vesicles are released by exocytosis into the synaptic cleft and bind to receptors on the postsynaptic membrane, leading to the transmission of neuronal information. Neurons in the brain are interconnected by thousands of synapses. Rapid neurotransmission is mediated mainly by excitatory glutamate synapses, in which the binding of glutamate to postsynaptic receptors

*1 Yokohama City University Graduate School of Medicine, Department of Physiology, Yokohama, Kanagawa, Japan.

*2 Keio University School of Medicine, Department of Neuropsychiatry, Tokyo, Japan.

\# These authors equally contributed to this work.

$\dagger$ Correspondence should be addressed: T. Takahashi, Yokohama City University Graduate School of Medicine, Department of Physiology, 3-9 Fukuura, Kanazawa-ku, Yokohama, Kanagawa 236-0004, Japan (e-mail: takahast@yokohama-cu. ac.jp). induces elevation of postsynaptic membrane potential (depolarization) and inhibitory gamma-aminobutyric acid (GABA) synapses where GABA binding to its receptors leads to a decrease in postsynaptic membrane potential (hyperpolarization) that depends on the chloride equilibrium potential. ${ }^{1), 2)}$

Psychiatric disorders such as depression, schizophrenia, and autism and neurological disorders (e.g., stroke, epilepsy, Parkinson's disease, and dementia) severely impair the quality of life of patients. The biological basis of these disorders including their onset, progression, and recovery process is still poorly elucidated, which prevents the development of novel diagnostics and therapeutics. Recent studies from animal disease models, genetics, and postmortem brains suggest that alteration of synaptic functions underlie these disorders. Among various synapses, glutamatergic and GABAergic synapses are considered to directly regulate the onset and status of neuronal diseases.

Glutamate synapses are the most abundant excitatory synapses in the brain and mediate the majority of neuronal functions. $\alpha$-amino-3-hydroxy-5methyl-4-isoxazole propionic acid receptor (AMPAR) is an ionotropic glutamate receptor. ${ }^{3), 4)}$ Glutamate 
binding activates AMPARs and elevates postsynaptic membrane potential by the influx of cations. There are four distinct subunits of AMPARs, GluA1, GluA2, GluA3, and GluA4, which assemble into tetramers to form a core functional ion channel. ${ }^{5), 6)}$ GluA1-3 are expressed in the majority of neurons in the nervous system of mature animals. On the other hand, GluA4 is primarily expressed early in development and in cerebellar granule neurons and some populations of interneurons in the mature brain. ${ }^{4), 7), 8)}$ $\mathrm{N}$-methyl-D-aspartate receptor (NMDAR) is another ionotropic glutamate receptor. NMDAR is blocked by magnesium at resting potential, and this blockade is released by depolarization through AMPAR activation leading to the influx of cations including calcium. Because AMPAR contributes to a major fraction of the glutamatergic synaptic current, ${ }^{9), 10)}$ AMPAR may be a promising translational target to tackle psychiatric and neurological disorders. However, despite its potential, translational approaches targeting AMPAR have not been successful. In this review, we discuss the current limitations of neuropsychiatric disorders and the need and potential of translational medicine of AMPAR.

\section{AMPAR trafficking and synaptic plasticity}

Experience such as learning alters neural circuits throughout development to adulthood, leading to an infinite diversity of neural functions in the brain, which is known as "neural plasticity". These circuit changes depend on the selective strengthening and weakening of synaptic efficacy in the brain. The most characterized forms of synaptic plasticity are long-term potentiation (LTP) and long-term depression (LTD), in which a short period of synaptic stimulation can trigger long-lasting strengthening (in LTP) or weakening (in LTD) of synaptic transmission. ${ }^{11)-14)}$ Postsynaptic addition or removal of AMPAR controls LTP and LTD.3),15)-18) Synaptic trafficking and addition of AMPAR is one of the most investigated synaptic molecular modifications underlying experience-dependent synaptic plasticity. ${ }^{19)}$ This molecular event was first characterized as a molecular mechanism of persistent strengthening of synaptic responses during LTP using in vitro hippocampal slices. ${ }^{20)-22)}$ In the hippocampal pyramidal synapses of mature rats, GluA1/2 and GluA2/3 heteromers are the major configuration of AMPARs. ${ }^{23), 24)}$ It has been considered that these subunit compositions are largely maintained in the brain, whereas the relative expression of AMPAR subunits exhibits some regional differences. ${ }^{4), 8), 24)}$
Subunit composition is considered to rule synaptic AMPAR trafficking. ${ }^{22)}$ GluA1-containing AMPARs are delivered and added into synapses during LTP in an activity-dependent manner, leading to an increase in AMPAR-mediated synaptic current. ${ }^{21)}$ In the early phase of LTP, GluA1 homomeric receptors, $\mathrm{Ca}^{2+}$ permeable AMPAR composition, are primarily delivered into synapses. ${ }^{25)}$ Synaptic delivery of GluA2/3 heteromers is constitutive and activity independent, which builds up the basal synaptic transmission, and GluA2/3 heteromers are considered to replace GluA1-containing AMPARs and maintain the increased synaptic transmission throughout LTP. ${ }^{3), 4), 16), 22), 24)}$ The role of synaptic AMPAR trafficking in experience-dependent neural plasticity was first reported in the developing rat barrel cortex, which receives sensory input from the whiskers. ${ }^{26)}$ Using viral-mediated in vivo gene transfer in combination with electrophysiological whole cell recording, we showed that GluA1-containing AMPARs are delivered to synapses formed from layer 4 to layer $2 / 3$ pyramidal neurons of the developing rat barrel cortex (postnatal day 12-14). This trafficking was prevented in the absence of whisker inputs. As was observed in LTP, GluA1-lacking (thus GluA2/3) AMPARs were delivered into synapses in an experience-independent manner. This study demonstrated that, in the developing rat barrel cortex, whiskerexperience drives GluA1-containing AMPARs into synapses leading to the potentiation of synaptic efficacy followed by replacement with GluA2/3, whose experience-independent constitutive synaptic delivery maintains elevated synaptic efficacy (Fig. 1). ${ }^{26)}$ Synaptic trafficking of AMPARs has been proven to underlie experience-dependent plasticity in other brain areas such as amygdala and hippocampus. Rumpel et al. showed that auditory fear learning drives GluA1-containing AMPARs into amygdala synapses. ${ }^{27)}$ Furthermore, blockade of synaptic delivery of GluA1-containing AMPARs in the amygdala by overexpression of the cytoplasmic portion of GluA1 (GluA1-ctail), which prevents synaptic delivery of GluA1-containing AMPARs by potential trapping of proteins required for trafficking attenuated formation of auditory fear learning, suggesting that GluA1-containing AMPAR delivery in the amygdala is required for fear leaning. ${ }^{27)}$ LTPlike synaptic potentiation was reported in an inhibitory avoidance (IA) task ${ }^{28)}$ : IA task, a hippocampus-dependent contextual fear learning. In this task, rodents are allowed to cross from a light box to a dark box, where an electric foot shock is delivered. 


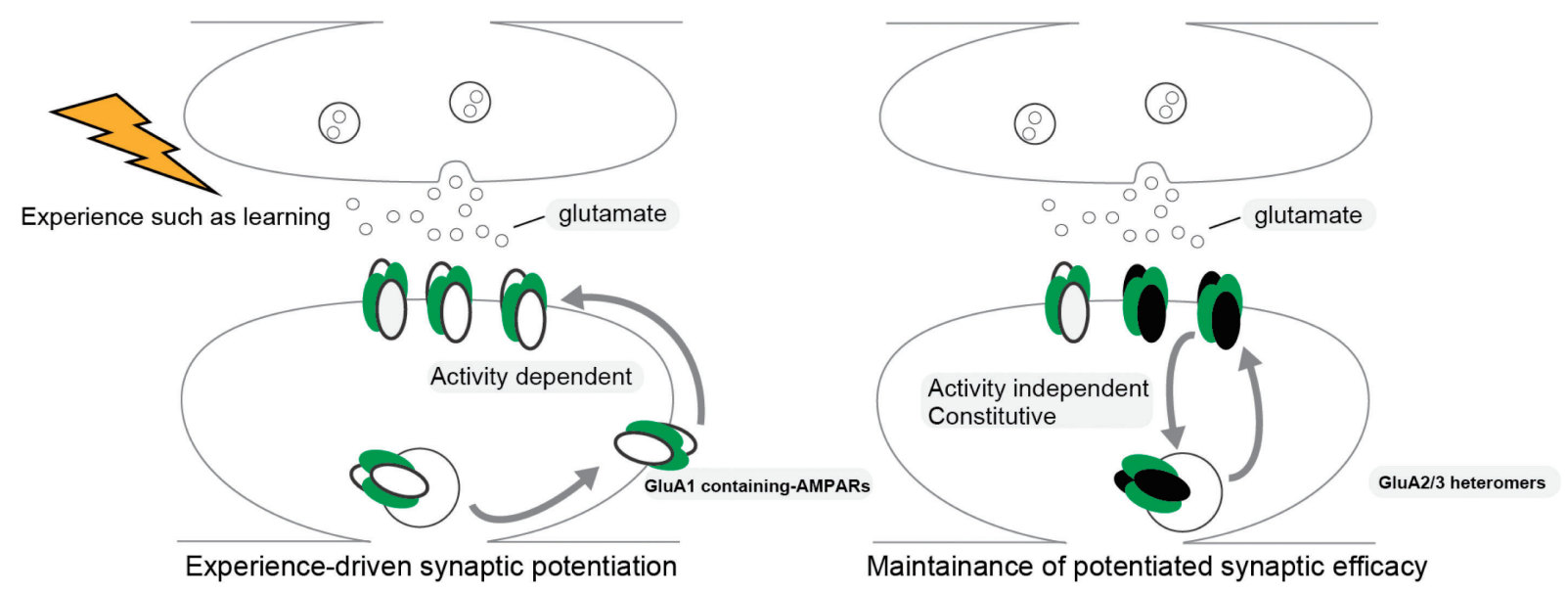

Fig. 1. Experience-dependent GluA1-containing AMPARs trafficking to the post-synaptic membrane. GluA1-containing AMPARs are trafficked to post-synaptic membranes in an experience-dependent manner, leading to the sustained potentiation of synaptic transmission, as is observed in LTP. GluA2/3 heteromers replace GluA1-containing AMPARs and are delivered to synapses in an experience-independent fashion, which maintains potentiated basal synaptic transmission.

Thus, animals learn to avoid the dark box and stay in the light box, which they do not naturally prefer. The latency to re-enter the dark box is prolonged when the animal establishes IA learning. Consistent with this study, we found that IA learning drives GluA1-containing AMPARs into hippocampal CA3CA1 synapses. ${ }^{29), 30)}$ Furthermore, the expression of GluA1-ctail in the dorsal hippocampus attenuated IA learning formation, indicating that synaptic trafficking of GluA1-containing AMPARs is required for hippocampus-dependent learning, as observed in the amygdala. ${ }^{29)}$ Do synaptically delivered AMPARs actually encode memory? To test this hypothesis, we generated a monoclonal antibody against GluA1 (called Z9139) and labelled the antibody with lightsensitive eosin so that we are able to inactivate GluA1 by light exposure in vitro and in vivo through chromophore-assisted light inactivation (CALI), which can disrupt the functions of target molecules using a photosensitizer producing short-lived reactive oxygen upon irradiation with light (Fig. 2A). ${ }^{31}$ CALI with eosin-labelled Z9139 selectively inactivated GluA1 homomeric AMPARs. ${ }^{31)}$ GluA1 homomeric AMPARs display conductance at negative but not at positive potentials, which is inward rectification, whereas GluA2-containing AMPARs such as GluA1/2 and GluA2/3 heteromers allow conductance at both negative and positive potentials. We observed increased inward rectification at hippocampal CA3-CA1 synapses within 2 hours after IA conditioning (Figs. 2B, C), which disappeared 24 hours after conditioning, indicating that IA learning transiently drives GluA1 homomeric AMPARs into CA3-CA1 synapses. ${ }^{31)}$ We injected eosin-labelled Z9139 into the dorsal hippocampus in combination with insertion of a light canula and conditioned these animals with an IA task (Fig. 2B). The light exposure of IA conditioned animals injected with eosin-labelled Z9139 decreased the latency to re-enter the dark box, indicating that disruption of GluA1 homomeric AMPARs erases fear memory (Fig. 2D). ${ }^{31)}$ This suggests that synaptically delivered GluA1 homomeric AMPARs with IA encode fear memory. These results demonstrated that synaptic AMPAR delivery is a fundamental molecular mechanism underlying experience-dependent neuronal plasticity throughout the brain. Thus, trafficking of AMPARs, and AMPARs themselves, may be a highly promising translational target.

\section{Imminent need to elucidate the pathophysiology of psychiatric disorders}

There are two major challenges in the field of psychiatry. First, because there are no established biological markers for psychiatric disorders, their diagnostic system is solely based on the symptoms that patients manifest. This principle is still the rule even in the 21st century. In fact, neither of two major diagnostic criteria in psychiatry, i.e., the International Statistical Classification of Diseases and Related Health Problems (ICD) ${ }^{32}$ by the World Health Organization and the Diagnostic and Statistical Manual of Mental Disorders (DSM) ${ }^{33}$ ) by the American Psychiatric Association, includes any 
A

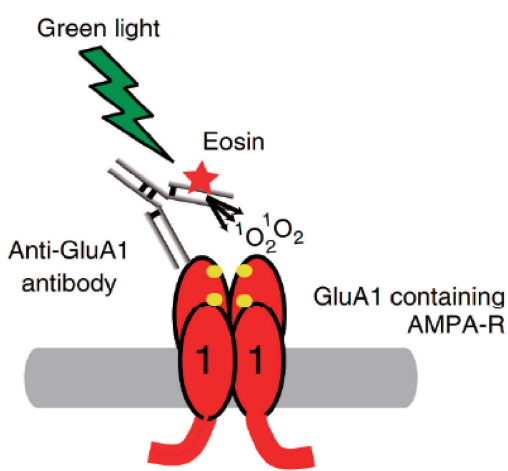

C

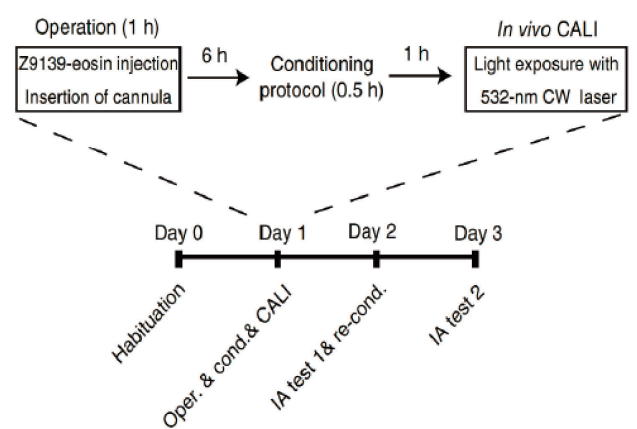

B

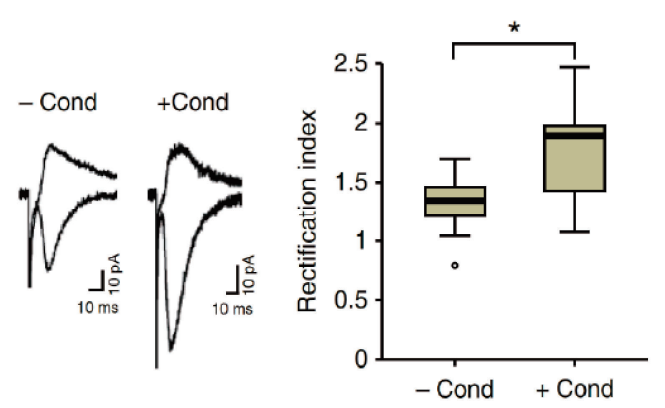

D

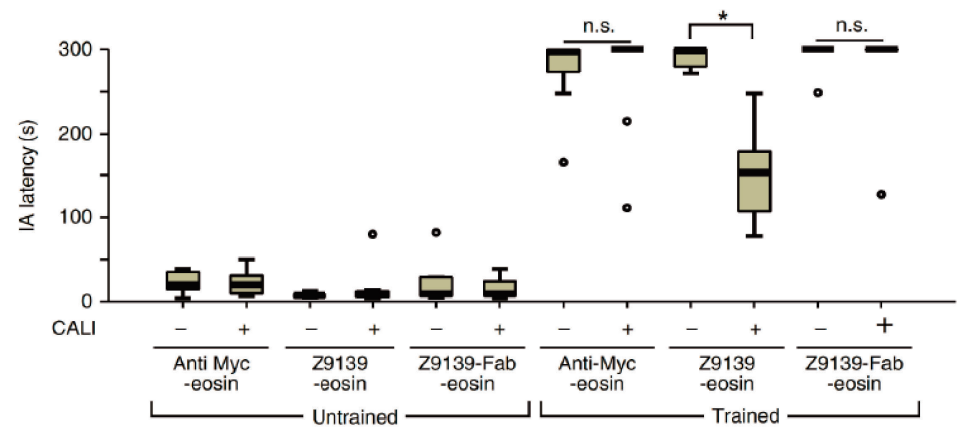

Fig. 2. In vivo CALI erases contextual fear memory. (A) Schematic representation of CALI for GluA1 using an anti-GluA1 monoclonal antibody (called Z9139) labeled with eosin, a photosensitizer. (B) IA learning increased the synaptic delivery of homomeric GluA1. Left: synaptic responses at the hippocampal CA3-CA1 synapses in acute brain slices obtained from animals with or without IA $1 \mathrm{~h}$ after conditioning. Right: average rectification index (the ratio of AMPA current of $-60 \mathrm{mV}$ to $+40 \mathrm{mV}$ ) at hippocampal CA3-CA1 synapses with or without conditioning $1 \mathrm{~h}$ after IA learning. Note that the rectification index is increased at hippocampal CA3-CA1 synapses of animals with IA learning compared with those animals without. (C) Experimental procedure for in vivo CALI in combination with IA learning. (D) In vivo CALI with Z9139-eosin erased hippocampus-dependent fear memory. Latency for reentering the dark box in untrained mice or mice trained using the IA task. Animals were treated with Z9139-eosin, anti-Myc-eosin, or Z9139-Fab-eosin, with or without CALI. Note that the latency to reenter the dark box for trained mice treated with Z9139-eosinCALI was shorter than those treated without CALI or with Myc-eosin-CALI. ${ }^{*} \mathrm{P}<0.001$. This derives from Ref. 31 .

biological marker for any disorder. This lack of an objective diagnostic system based on biological markers often results in treatment delay, misdiagnosis, and resultant inappropriate treatment and unfavorable outcomes ${ }^{34), 35)}$ as well as high social cost. $^{36)}$ Second, currently available drugs for psychiatric disorders can relieve symptoms to some extent, but they do not cure the disorders. ${ }^{37)}$ Furthermore, there is a significant proportion of patients who do not respond to these drugs, which is referred to as treatment resistance. For example, approximately one-third of patients with depression and schizophrenia do not attain clinical response with antidepressants and antipsychotics, ${ }^{38), 39)}$ respectively. Although pharmaceutical companies have attempted to develop new drugs for psychiatric disorders, many clinical trials have failed recently, and there are only a few candidates in the pipeline. In the light of such an unpromising climate in this field, major megapharmaceutical companies withdrew from the drug market for the central nervous system. The most significant reason for this frustrating situation is the fact that the pathophysiology of psychiatric disorders remains largely unclear.

Previous brain imaging findings of two major psychiatric disorders, depression and schizophrenia, are summarized below as examples. In depression research, the serotoninergic system is the most investigated neural system. Previous post-mortem, in vivo brain imaging, and metabolite studies have shown reductions in the constituents in this system such as serotonin transporters ${ }^{40)}$ and $5-\mathrm{HT}_{1 \mathrm{~A}}$ receptors. $^{41)}$ Alterations are also the case for the norepinephrine system in patients with depression. ${ }^{42), 43)}$ 
Previous brain imaging studies attempted to find regional differences in biomarkers between patients with depression and healthy controls and actually have found the alteration in many regions. ${ }^{44)-46)}$ However, importantly, these findings are not always consistent among, even within, imaging modalities. The dopaminergic system has been most extensively investigated in an attempt to elucidate the pathophysiology of schizophrenia and to devise therapeutics, ${ }^{47)}$ which developed the concept of the dopaminergic hypothesis of schizophrenia. However, there are a number of phenomena that cannot be explained with this hypothesis, such as treatment resistance to dopamine antagonists ${ }^{39)}$ and superior efficacy of clozapine despite its low affinity to dopamine receptors. ${ }^{48)}$ Several lines of evidence suggest that hypofunction of the glutamatergic neural system is also involved in the pathogenesis of schizophrenia. The classic support for this hypothesis is the acute psychomimetic effects of non-competitive antagonists of NMDARs such as ketamine ${ }^{49}$ and phencyclidine. ${ }^{50)}$ However, these findings together with previous studies of anatomical, functional, and molecular alterations in schizophrenia are mixed and inconsistent, ${ }^{51)-58)}$ and they have not identified neural regions or tracts responsible for the pathophysiology of this illness.

One of the critical limitations in previous psychiatric research in humans is that it has attempted to characterize phenomenon that patients with each illness manifest in comparison to healthy people or other patient groups, but these have largely failed to underpin the molecular basis of the illness. In fact, despite accumulating evidence, again, there has been no diagnostic system based on biological markers. ${ }^{32), 33)}$ Moreover, it is also a fact that a significant proportion of psychiatric patients do not respond to current therapeutics. ${ }^{38), 39)}$ In this context, a totally new molecular target beyond the conventional schemes, such as the monoaminergic hypothesis for depression and the dopaminergic or NMDA hypothesis for schizophrenia, has been long desired in psychiatry. If this becomes true, it will have the potential to be utilized for the development of a new molecular-based diagnostic system as well as drugs that have brand-new mechanisms of action based on a precise understanding of the pathophysiology of psychiatric disorders.

There has been a growing interest in AMPARs as a new molecular target of investigations of pathophysiology in psychiatric disorders as evidence from animal models has accumulated. ${ }^{59)-63)}$ Indeed, as described in the previous section, there is a huge body of robust data on the neuronal functions of AMPARs with experimental animals in the literature. ${ }^{26)-31)}$ Furthermore, mutations of AMPARs have been reported in neuropsychiatric disorders such as schizophrenia, autism and metal retardation, ${ }^{64)-67)}$ indicating the importance of AMPARs in neuropsychiatric disorders. On the other hand, it is also true that there is still a huge gap between the bench and bedside especially due to the lack of means of translating those previous findings at the bench to actual patients in clinical settings. This is simply because it was not possible to visualize AMPARs in the living human brain. There have been postmortem brain studies that measure AMPARs in the brain. According to systematic literature reviews, there are differences in AMPAR subunit expression and receptor binding in the postmortem brain between patients with psychiatric conditions, including schizophrenia, depression, and addictive disorders, and healthy controls ${ }^{68)}$ (Uchida et al. and Koizumi et al., in preparation for publication); however, the findings regarding their relative quantity in comparison to healthy controls and the affected regions were inconsistent across the studies. Degrading changes after death and the activitydependent nature of AMPARs render human postmortem studies challenging. ${ }^{68)}$ Moreover, subjects included in these post-mortem studies were not comprehensively characterized in terms of their diagnosis and illness severity. Such a stagnating situation clearly highlighted the necessity for examining AMPARs in the living brain of well-characterized patients with psychiatric disorders in the realworld.

\section{Current challenge in developing novel thera- peutics for neurological disorders}

Novel diagnostic and therapeutic methods for neurological diseases such as stroke, epilepsy, Parkinson's disease, and Alzheimer's disease (AD) are in high demand because current diagnostics and therapeutics are still insufficient in improving their unfavorable prognoses and reducing social burdens. ${ }^{69)}$

Stroke. Neuroscientists and clinicians have explored potential drugs that could augment functional recovery after brain damage such as stroke. Among various kinds of agents, d-amphetamine and serotonin reuptake inhibitors have been prime candidates as rehabilitation enhancers. In fact, damphetamine stimulates the release of the catecholamines and increases extracellular catecholamines by 
blocking their reuptake. Motor activation after damphetamine injection was observed in decerebrate cats, which was the first report on the influence of d-amphetamine upon motor functions. ${ }^{70)}$ A spectrofluorometer study of brain samples showed that unilateral middle cerebellar artery occlusion yielded variable changes in norepinephrine-epinephrine contents in cerebral tissues. ${ }^{71)}$ Based on these previous reports, it was revealed that d-amphetamine injection with rehabilitative training in a rat cortical injury model promoted motor functional recovery. The first report on functional recovery with damphetamine showed that hemiplegic rats treated with d-amphetamine exhibited continuous recovery in the beam-walking task. ${ }^{72)}$ A following study revealed that d-amphetamine recovered forelimb dexterity in a reach-to-grasp task over 3 weeks in rats with unilateral lesions in the cerebral cortex. ${ }^{73)}$ Contrary to these promising effects in rats, the effects are limited in non-human primates and inconsistent in humans. ${ }^{74}$ A recent randomized clinical trial reported in 2018 showed that d-amphetamine did not alter rehabilitation effects after stroke independent of lesion site and severity. ${ }^{75)}$ Although d-amphetamine promotes plastic changes such as axonal growth, synaptogenesis, and LTP induction, ${ }^{76), 77)}$ d-amphetamine can induce hyperexcitability, which may result in a low signal-to-noise ratio between circuits required for functional recovery and others. ${ }^{78)}$ Selective serotonin reuptake inhibitors (SSRIs), which are mainly used as antidepressant drugs, have also been examined as a candidate for pharmacological restorative therapy. According to a 3-month placebo-controlled randomized clinical trial including 42 severely disabled hemiplegic patients who were receiving physical therapy, fluoxetine demonstrated the greatest improvements in motor performance, compared with placebo and tetracyclic antidepressants. ${ }^{79}$ This finding was corroborated by a functional magnetic resonance imaging (MRI) study showing that fluoxetine evoked motor cortical excitability in stroke patients. ${ }^{80}$ ) In animal models, fluoxetine restored ocular dominant plasticity in adult rodents via the upregulation of brain-derived neurotrophic factors. ${ }^{81)}$ On the other hand, it should be noted that there are no reports on the efficacy of fluoxetine in improving motor functions after cortical injury in animal models. Despite the lack of proof in animal models, the effects of fluoxetine on motor function recovery have been tested for the past 10 years, yielding mixed results. For example, the FLAME (fluoxetine for motor recovery after acute ischaemic stroke) study, a randomized placebocontrolled trial reported in 2011, showed that continuous oral fluoxetine combined with physiotherapy promoted motor functional recovery. ${ }^{82)}$ In contrast, the FOCUS (Fluoxetine Or Control Under Supervision) trial in 2019 demonstrated that oral fluoxetine for six months after the onset did not change the functional status in patients with some neurological deficits. ${ }^{83)}$ Moreover, a subgroup of patients with motor deficits did not show any significant motor function recovery. In 2020, the meta-analysis of 13 randomized controlled trials with a total of 4,145 patients that evaluated the efficacy of fluoxetine in terms of recovery of stroke concluded that fluoxetine does not reduce disability and dependency after stroke. ${ }^{84)}$ Thus, these negative results of d-amphetamine and SSRIs for restorative therapy clearly indicates that it is crucial to modify specific circuits necessary for functional recovery based on a substantial enhancement of circuitspecific plasticity rather than the induction of global alteration of neurotransmitters. Considering that glutamatergic synapses play central roles in neuronal functions, synaptic pharmacology targeting AMPARs should be a reasonable translational approach for revising therapeutic strategies to achieve functional recovery after traumatic damage to central nervous system such as stroke. Furthermore, there is an enormous need for imaging tools to visualize changes in AMPARs induced during the recovery process in living humans, so as to evaluate functional restoration with tangible biological evidence and optimize methods of intervention during rehabilitation.

Epilepsy. Epilepsy is a neurological disorder characterized by recurrent epileptic seizures induced by overexcitation of neurons. Symptoms can be determined according to the brain regions responsible for seizure onset. ${ }^{85}$ In case these brain regions are limited to focal area, patients show impaired awareness, motor and nonmotor seizures. Expansion of the seizure onset areas to the whole brain leads to generalized convulsion. The lifetime prevalence of epilepsy is reported to be 7.60 per 1,000 population, and its incidence shows two peaks in children and older-aged populations. ${ }^{86)}$ Epilepsy is progressive in some cases, and the affected area sometimes spreads widely over the whole brain over months to years, increasing severity of the symptoms. ${ }^{87}$ )

The initial treatment for epilepsy usually begins with antiepileptic drugs (AEDs). The choice of AEDs is usually determined according to seizure type, and 
an appropriate dose of AEDs suppresses epileptic seizures in approximately two-thirds of patients. ${ }^{86)}$ Classical targets of AEDs are sodium channels and the GABAergic system. Recently, an AED with a new mechanism as a selective non-competitive antagonist of AMPARs became available in clinical practice, expanding the range of drug treatment options. ${ }^{88)}$ On the other hand, seizures cannot be controlled with AEDs alone in approximately onethird of the patients, which is referred to as refractory epilepsy. Surgical treatment is considered for some refractory epilepsy patients. One of the most common surgical intervention is a focal resection. Focal resection is indicated for patients with refractory epilepsy whose epileptogenic focus has been identified. Favorable outcomes such as postoperative elimination of epileptic seizures can be expected in patients who suffer from mesial temporal lobe epilepsy with hippocampal sclerosis and partial epilepsy with well-defined lesions. ${ }^{89), 90)}$ Even for those whose obvious pathological lesion is not observed, if an epileptogenic focus can be predicted with clinical symptoms and scalp electroencephalogram (EEG) and by chronic intracranial EEG recording, focal resection is performed. ${ }^{91)}$ Although surgical treatment is effective, this treatment option is under-used because of technical difficulties in identifying an epileptogenic focus before surgery. Thus, there is an exigent need to develop non-invasive imaging technology to locate the epileptogenic focus. ${ }^{92)}$ Because an increase in AMPARs was observed in surgically resected brain tissues responsible for seizure onset, ${ }^{93}$ ) a technology to visualize AMPARs in patients with epilepsy is expected to lead to more frequent and successful surgical treatment for this difficult-to-treat population.

Neurodegenerative disease. Although conventional neurotransmitter replacement therapy has yielded some symptomatic relief for patients with neurodegenerative diseases, it does not cure them or offer complete recoveries to date. For example, Parkinson's disease, which is a neurodegenerative disease accompanied by $\alpha$-synuclein accumulations primarily in the substantia nigra and dopamine deficits, ${ }^{94)}$ is treated with L-dopa replacement therapy. ${ }^{95)}$ This treatment transiently relieves motor symptoms in the early phase with the elevation of dopamine in the central nervous system, but often cause difficult-to-treat motor complications such as dyskinesia and wearing off in the late phase. More importantly, L-dopa replacement therapy does not suppress disease progression. ${ }^{96), 97)}$ This is also true for Alzheimer's disease; replacement of acetylcholine with acetylcholine esterase inhibitors (e.g., donepezil, galantamine, and rivastigmine) does not result in satisfactory results for memory deficits. ${ }^{98), 99)}$

Dementia due to neurodegeneration is considered to be caused by pathological aggregates such as $\mathrm{A} \beta$, tau and $\alpha$-synuclein and subsequent neural atrophy. For example, the $\mathrm{A} \beta$-tauopathy cascade has been considered to be the central pathology of AD. In this cascade, amyloid precursor protein (APP) is cleaved by $\beta$-secretase (BACE1) and $\gamma$-secretase, which yields $\mathrm{A} \beta \mathrm{s} .{ }^{100), 101)}$ In $\mathrm{A} \beta \mathrm{s}, \mathrm{A} \beta 42$ oligomers have neurotoxic effects and forms aggregates. A $\beta 42$ aggregate is called a senile plaque and can be an initiator of abnormal tau-phosphorylation. ${ }^{102)}$ A $\beta 42$ aggregates and phosphorylated tau can promote neural atrophy, which in turn can result in memory deficits. ${ }^{103)}$ A possibility that $\mathrm{A} \beta 42$ aggregates might be a therapeutic target of AD was pointed out by Schenk et al. In this report, AD model mice that received an injection of an antibody against $\mathrm{A} \beta 42$ did not exhibit $\mathrm{A} \beta 42$ aggregations. ${ }^{104)}$ Based on this finding, anti-A $\beta$ antibodies (e.g., solanezumab, crenezumab, bapinezmab, aducanumab, and gantenerumab) have been developed as therapeutics. In 2016, interim results of the PRIME study confirmed the safety and tolerability of aducanumab and found that it reduced $\mathrm{A} \beta$ deposition in the human brain measured using $\mathrm{A} \beta$ positron emission tomography (PET) imaging of patients with cognitive decline. ${ }^{105)}$ The PRIME study targeted not only patients with mild AD but also those with mild cognitive impairment (MCI). On the other hand, the EXPEDITION3 study targeting patients with mild to moderate AD reported that solanezumab did not suppress cognitive decline in 2014. ${ }^{106)}$ The latter result suggested that the use of anti-A $\beta$ antibodies is too late to suppress neurodegenerative progression for those with mild to moderate AD.

Recently, neurodegenerative diseases have also been considered as synapse diseases. ${ }^{107)}$ Indeed, synaptic dysfunction is observed from the earliest stage of disease progression of AD. ${ }^{108)}$ A human brain autopsy study showed that the degree of synaptic reduction correlates with the severity of cognitive dysfunction and the duration of illness in $\mathrm{AD}$ patients. ${ }^{109)}$ Immunohistochemical studies have also shown that AMPARs are decreased before neuronal cell death. ${ }^{110), 111)}$ Moreover, according to a study using $\mathrm{AD}$ model animals, secretion of $\mathrm{A} \beta$ into the synaptic cleft likely causes endocytosis of AMPARs on the synaptic surface, resulting in a decrease in 
the number of synapses. ${ }^{112), 113)}$ In another transgenic mice study, difficulties in spatial memory tasks were associated with LTP deficits, but not with synaptic or cellular loss. ${ }^{114)}$ These findings showed that not synaptic or cellular loss but early synaptic dysfunction occurs before $\mathrm{A} \beta$ plaque formation. Notably, epileptic activity is often associated with AD. ${ }^{115), 116)}$ Recording with intracranial foramen ovale electrodes detected epileptiform spikes in the mesial temporal lobe of patients with AD. ${ }^{116)}$ In $\mathrm{AD}$ model mice, two-photon $\mathrm{Ca}^{2+}$ imaging exhibited that soluble $\mathrm{A} \beta$ increased the hyperactive neural population in hippocampus $\mathrm{CA} 1$ before $\mathrm{A} \beta$ plaque deposition. ${ }^{117}$ ) These results suggested that hyperactive neurons are mixed with hypofunctional neurons. Hyperactive neurons might contain increased synaptic AMPARs and cause epileptic seizures. Neurons with hypofunction in $\mathrm{AD}$ patients can be produced with pathogenic proteins such as $\mathrm{A} \beta$ and tau. Consistent with this concept, certain classes of AEDs have diseasemodifying properties in AD model animals. For example, chronic lamotrigine administration in APP/PS1(presenilin 1) transgenic mice attenuated learning deficits following the reduction of epileptic spike activity in the cortex and the hippocampus. ${ }^{118)}$ The underlying mechanism of the production of hyperactive neurons remains to be elucidated. One possibility is that functional compensation is induced in these hyperactive neurons by the loss of function of fractions of neurons with pathological changes. These observations highlight the importance of detecting functional and malfunctional circuits in the brains of $\mathrm{AD}$ patients, leading to a novel concept in therapeutics, in which maintaining or strengthening healthy synapses or neural circuits in MCI due to AD or early AD may reduce the degenerative progression. Thus, early pathological changes in glutamatergic synaptic functions have now been considered to be a therapeutic target for $\mathrm{AD}$. However, because there were no methods that can reliably detect glutamatergic synaptic dysfunction in the early, potentially reversible phase in living human brain, a feasible treatment target used to be the pathological aggregates such as $\mathrm{A} \beta$ and tau in the late irreversible phase. However, previous clinical trials targeting $\mathrm{A} \beta$ in neurodegenerative diseases have not been successful. This frustrating situation underscores the need for a novel tool to examine glutamatergic synapses in the living human brain. Among constituents of glutamate synapses, AMPARs have garnered widespread attention in the light of abundant evidence on the important roles of AMPARs in AD model animals. ${ }^{119)-121)}$ Characterization of AMPARs in AD patients is expected to be a crucial step toward elucidation of the pathogenesis and development of early diagnostics and novel therapeutics. However, this was not possible for years simply due to the lack of technology to visualize AMPARs in living patients with $\mathrm{AD}$.

\section{Limitations of current neuropsychiatric diseases animal models}

Elucidation of biological mechanisms underlying neuropsychiatric disorders is indispensable to promote a translational approach, which can lead to the development of novel diagnostics and therapeutics. The initial step at the bench is to establish appropriate disease animal models. ${ }^{122)}$ However, there are two major challenges to achieve this. First, there are technical difficulties to apply the conventional strategy of creating animal models to neuropsychiatric disorders. It is a current standard to produce transgenic animals carrying genetic mutations identified in human patients with a family history of certain diseases. ${ }^{123), 124)}$ However, mutations among multiple genes in combination with environmental factors are involved in developing major neuropsychiatric disorders. ${ }^{125)}$ Second, psychiatric and psychological symptoms (e.g., depressive mood, hallucination, anxiety) that patients experience are essentially subjective, which may not be appropriately reproduced in animals. ${ }^{126)}$ Moreover, patients with potentially different biological backgrounds often exhibit similar symptoms and are categorized into the same diagnosis. Such heterogenous features of neuropsychiatric disorders in humans should be acknowledged when data from neuropsychiatric disease animal models are interpreted. ${ }^{127)}$ Thus, there is an imminent need to develop reliable and valid neuropsychiatric disease animal models for a successful translational approach.

Synaptic functions are the central effector of these complicated multiple genetic and environmental etiologies, and these pathogenic factors may result in similar alterations of synaptic functions. ${ }^{128)}$ Considering the fact that glutamate AMPAR is one of the most fundamental components of neurotransmission in the brain, characterization of neuropsychiatric disorders with a focus on AMPAR in actual living patients has the potential to delineate the biological basis of symptomatology of neuropsychiatric disorders that result from a variety of etiologies. This in turn could lead to the optimization and categorization of numerous animal models based 
on the alteration of synaptic functions, i.e., from bedside to bench. In this context, the technology to visualize AMPARs in living human brain has also long been desired to move the field forward.

\section{Synaptic AMPAR trafficking as a translational target for enhancing functional recovery}

Functional recovery after brain damage such as stroke is considered to be a plastic event with functional compensation in intact brain areas. ${ }^{129)}$ We have previously found that visual deprivation drives AMPARs in layer 4 to layer 2/3 pyramidal synapses in the juvenile barrel cortex leading to the enhancement of the function of whisker-barrel systems, which may help animals with visual loss to capture spatial information with their whiskers. ${ }^{130)}$ In addition, rehabilitation in hemiplegia promotes functional reorganization in intact peri-lesional regions. ${ }^{131)}$ These led us to hypothesize that synaptic AMPAR trafficking can be a translational target for the functional recovery after brain damage such as stroke. For restoring motor function in hemiplegic patients, the specific activation of motor circuits is needed. Here, we introduce our recent identification of a small compound, edonerpic maleate (also called T817), which accelerates motor function recovery after traumatic damage of the central nervous system including stroke by the facilitation of synaptic AMPARs trafficking. ${ }^{7)}$ After a series of in vitro screening of the library of compounds to modify neuronal morphology, we focused on edonerpic maleate (T-817MA) to monitor its effect on experience-dependent synaptic AMPAR trafficking. As was described above, whisker-experience drives GluA1containing AMPARs into synapses formed from layer 4 to layer $2 / 3$ pyramidal neurons of developing rodent barrel cortex. ${ }^{26}$ ) This experience-dependent synaptic GluA1-containing AMPAR trafficking ceases by juvenile age when the barrel cortex is functionally matured. ${ }^{130)}$ We administered edonerpic maleate to adult mice and examined synaptic functions at layer 4-2/3 pyramidal synapses with whole cell recordings of acute brain slices. We found an increased AMPAR-mediated synaptic current at these synapses of animals treated with edonerpic maleate compared with vehicle-treated animals. The increase of AMPAR-mediated synaptic current with edonerpic maleate was abolished in the absence of whiskers, indicating that edonerpic maleate facilitates synaptic AMPAR (GluA1-containing AMPAR, see also below) trafficking in an experience-dependent manner (Fig. 3A). ${ }^{7)} \mathrm{A}$ target protein of edonerpic maleate appeared to be CRMP2 (collapsin-responsemediator-protein 2), which was first identified as a downstream molecule of semaphorin (Fig. 3A). ${ }^{132}$ ) The semaphorin family was initially isolated as a chemorepellent of developing axons ${ }^{133), 134)}$ and later reported to regulate synaptic functions. ${ }^{135), 136)}$ Accordingly, CRMP2 was also reported to regulate dendritic spine morphology. ${ }^{137)-139)}$ The facilitation of experience-dependent synaptic AMPAR delivery with edonerpic maleate was abolished in CRMP2deficient mice, demonstrating that the effect of edonerpic maleate on synaptic AMPAR delivery is mediated by binding to CRMP2. ${ }^{7)}$ Dephosphorylated (activated) actin depolarizing factor $(\mathrm{ADF}) /$ cofilin increases actin turnover and facilitates AMPARs trafficking during LTP. ${ }^{140)}$ Edonerpic maleate-induced facilitation of AMPAR trafficking was prevented by the dominant-negative form of $\mathrm{ADF} /$ cofilin. Thus, edonerpic maleate/CRMP2 complex increased dephosphorylated (thus activated) ADF/ cofilin, which leads to facilitation of AMPAR trafficking. ${ }^{7)}$ Based on the pharmacological action of edonerpic maleate, we applied edonerpic maleate to acute brain injury models to examine if it accelerates rehabilitation. In a rodent model, mice were administered edonerpic maleate or vehicle for 21 days after cryogenic injury. In this examination, the group of mice with edonerpic maleate administration in combination with rehabilitative training exhibited remarkably greater improvements in a reach-to-grasp task compared with a control group. Of note, mice with edonerpic maleate administration without rehabilitative training showed no improvements (Fig. 3B). ${ }^{7)}$ These contrasting results suggested that edonerpic maleate accelerates motor function recovery in a training-dependent fashion. Mice administered edonerpic maleate 3 days after cryogenic injury also showed motor function recovery. ${ }^{7)}$ Collectively, edonerpic maleate showed rehabilitation accelerating effects in a rodent cryogenic injury model with independent dose and its priming timing. Edonerpic maleate-induced augmentation of functional recovery was accompanied by the increase in AMPARmediated synaptic currents in the peri-injured brain region and was prevented by the expression of GluA1-ctail in these areas, indicating that edonerpic maleate facilitates training-dependent synaptic delivery of GluA1-containing AMPARs leading to the acceleration of functional recovery with edonerpic maleate (Figs. 3A, B). ${ }^{7}$ Consistent with the electrophysiological experiments, the effect of ednonerpic maleate on functional recovery was blocked in 
A
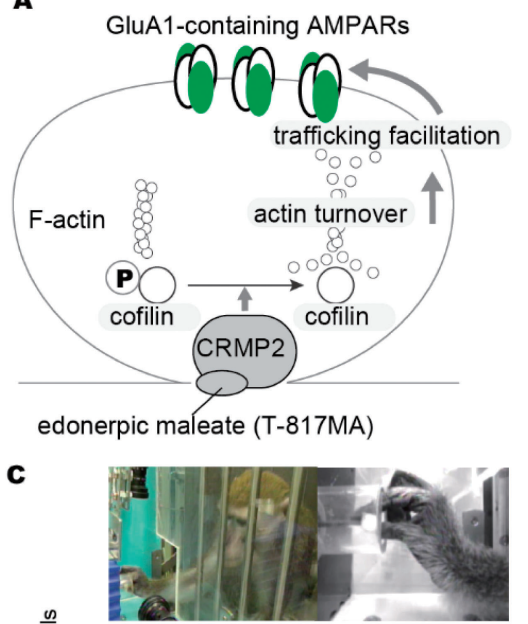

B edonerpic maleate $(\mathrm{T}-817 \mathrm{MA})+$ rehabilitation

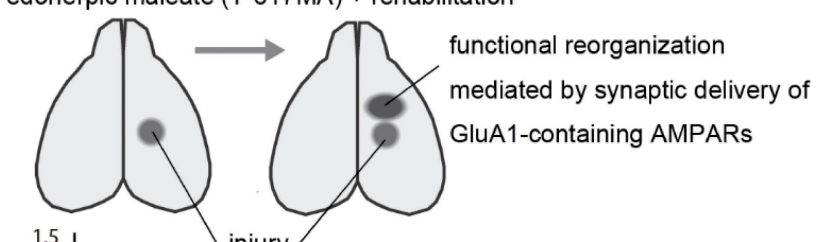

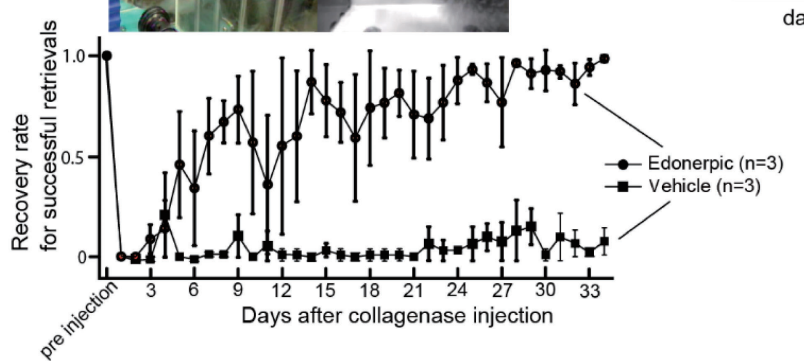

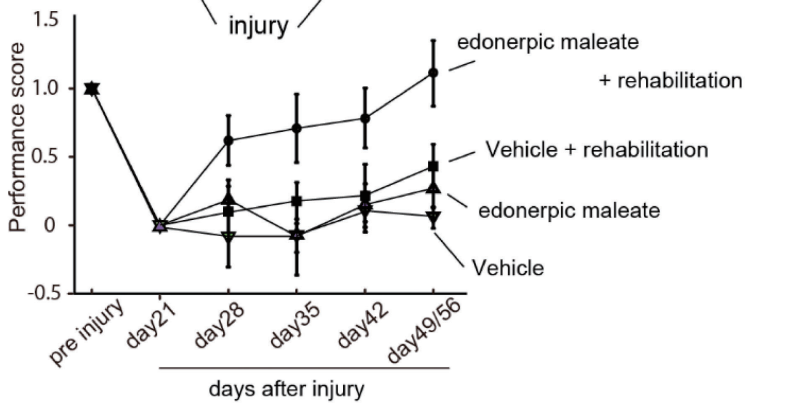

Fig. 3. An action of edonerpic maleate (T-817MA) and its efficacy on motor function recovery after brain damage. (A) Facilitation of edonerpic maleate on training (and experience)-dependent synaptic GluA1-contaning AMPAR trafficking. Edonerpic maleateCRMP2 complex dephosphorylates ADF/cofilin, which activates ADF/cofilin and promotes AMPAR trafficking to post-synaptic membranes, presumably via an increase in actin turnover. (B) In reach-to-grasp task with mice, edonerpic maleate augments motor function recovery after brain damage in a training-dependent manner. Edonerpic maleate facilitates the synaptic trafficking of GluA1containing AMPARs in a peri-injured region. (C) In a non-human primate, edonerpic maleate drastically promotes dexterity of a paralytic upper limb after internal capsule hemorrhage. This derives from Ref. 7.

CRMP2-deficient mice, suggesting that this effect is mediated by the binding of ednonerpic maleate to CRMP2. ${ }^{7)}$ In a non-human primate model, Macaca fascicularis administered with edonerpic maleate after the induction of internal capsule hemorrhage also showed a more drastic recovery in a dexterity task than the control group (Fig. 3C). ${ }^{7)}$ These transspecies effects of edonerpic maleate for functional restoration should be emphasized to translate the results of a basic study to clinical trials. From 2019 to today, a Phase-II trial is being conducted to evaluate the efficacy of edonerpic maleate on restoring motor function in hemiplegia patients in Japan (JapicCTI194633).

Despite the potentials of edonerpic maleate as a plasticity enhancer, its application to neurodegenerative diseases such as PD and amyotrophic lateral sclerosis (ALS) is challenging. As neurodegenerative diseases progress, compensatory circuits responsible for maintaining motor functions may change, and edonerpic maleate can enhance these circuits to sustain or augment motor function. However, this should be combined with therapies to neutralize potential toxic pathogenic proteins.

\section{Development of a PET tracer to visualize and quantify the density of AMPAR in living human brains}

As described above, it is crucial to evaluate AMPAR in the living human brain to elucidate the biological basis of neuropsychiatric disorders with the goal of developing novel diagnostics and therapeutics based on tangible biological evidence. Therefore, a technology to visualize AMPARs in living human brains has long been desired, which has led to extensive efforts to develop PET tracers for AMPAR. However, many previous efforts have been unsuccessful. ${ }^{141)}$ PET tracers for AMPAR have been designed and radiolabeled to assess AMPAR-binding characteristics, which are largely divided into two 
groups, antagonists and potentiators. ${ }^{142)}$ These are also subdivided into competitive or noncompetitive for glutamate. Compared with noncompetitive antagonists, fewer tracers based on potentiators have been reported. ${ }^{141)}$ For example, $\left[{ }^{11} \mathrm{C}\right] \mathrm{HMS} 011$, a noncompetitive antagonist of AMPAR, reached clinical evaluation. ${ }^{143), 144)}$ However, this tracer was reported to be unsuitable for practical PET imaging with a small dynamic range in the brain, which could be due to its pharmacodynamic behavior as a substrate of P-glycoprotein, a main efflux transporter expressed in blood-brain barrier (BBB). ${ }^{144)}$ Furthermore, other AMPAR antagonists have been developed as PET tracers; however, the development of these tracers were stopped during preclinical evaluation for the following reasons: 1) the binding patterns in the brain were likely a combination of regional blood flow and nonspecific binding, 2) brain uptake levels were too low to delineate binding potential in animals, and 3) no specific binding was observed with PET imaging in animals due to insufficient affinity in vivo. ${ }^{145), 146)}$ Likewise, AMPAR potentiators also share the same problems with their development, which showed a rapid decrease in the brain content, a uniform distribution, and high nonspecific binding due to their low affinity. In conclusion, an ideal PET tracer for AMPAR requires outstanding properties including high BBB penetration, low nonspecific binding, and high binding potential.

We have recently developed the first PET tracer for AMPARs, named $\left[{ }^{11} \mathrm{C}\right] \mathrm{K}-2$, which enables the visualization and quantification of AMPAR density in living human brains. ${ }^{147)}$ As candidates of PET tracer for AMPARs, we focused on noncompetitive positive allosteric modulators (PAMs), which do not compete with glutamate for binding to AMPARs and have high permeability of the BBB. Based on the chemical structure and affinity, we selected 4-[2(phenylsulphonylamino)ethylthio]-2,6-difuluoro-phenoxyacetamide (PEPA) for radiolabeling with a $\left[{ }^{11} \mathrm{C}\right]$ methyl group. We designed a ${ }^{11} \mathrm{C}$-labelled derivative of PEPA and finally produced $\left[{ }^{11} \mathrm{C}\right] \mathrm{K}-2$ (Fig. 4A). ${ }^{147)}$ Using in vitro and in vivo experimental approach, we accumulated evidence that $\left[{ }^{11} \mathrm{C}\right] \mathrm{K}-2$ exhibited specific binding to AMPARs as follows: 1) K-2 application potentiated AMPAR-mediated synaptic current at a therapeutic dose, as was observed with PEPA; 2) $\left[{ }^{11} \mathrm{C}\right] \mathrm{K}-2$ uptake was decreased in the striatum where AMPAR expression was knocked down with a short hairpin RNA technique (Fig. 4B); and 3) off-target binding assays proved that K-2 does not bind to 160 major proteins expressed in the central nervous system. ${ }^{147)}$ Furthermore, PET imaging of healthy subjects with $\left[{ }^{11} \mathrm{C} \mid \mathrm{K}-2\right.$ confirmed its reversible binding using Logan graphical analysis (Figs. 4C, D). ${ }^{147)}$ We also conducted a $\left[{ }^{11} \mathrm{C}\right] \mathrm{K}-2$ PET study to measure AMPAR density in patients with mesial temporal lobe epilepsy who were planned to undergo a surgery to resect the epileptogenic focus and then quantified AMPAR protein distribution in surgical specimens. As a result, we detected increased uptake of $\left[{ }^{11} \mathrm{C}\right] \mathrm{K}-2$ in the epileptogenic focus, and the uptake was closely correlated with the local AMPAR protein distribution in the resected surgical specimens from the same individuals (Figs. 4E, F). ${ }^{147}$ ) These results demonstrated that $\left[{ }^{11} \mathrm{C}\right] \mathrm{K}-2$ is a potent PET tracer for AMPARs.

\section{Ongoing clinical trials with $\left[{ }^{11} \mathrm{C}\right] \mathrm{K}-2$}

Approximately one-third of patients with epilepsy are drug resistant, and surgical resection of the epileptogenic focus is often effective to control seizures of these patients. However, due to technical limitations to non-invasively identify the epileptogenic focus, there are still few surgical cases. In our previous exploratory clinical study, we observed elevated uptake of $\left[{ }^{11} \mathrm{C}\right] \mathrm{K}-2$ in the epileptogenic focus of patients with mesial temporal lobe epilepsy. We are currently conducting a clinical trial to examine the potential of $\left[{ }^{11} \mathrm{C}\right] \mathrm{K}-2$ as a diagnostic tool to locate the epileptogenic focus with high sensitivity and specificity in comparison with conventional multiple assessments with ${ }^{18} \mathrm{~F}$-fluorodeoxyglucose(FDG)-PET, MRI, magnetoencephalography (MEG), cerebral blood flow scintigraphy (SPECT), and video-electroencephalography (EEG) (Table 1). If this diagnostic method is proven to be superior, it could increase the number of successful surgical cases.

PET scans of $\left[{ }^{11} \mathrm{C} \mid \mathrm{K}-2\right.$ are also incorporated in the clinical trial to examine the efficacy of edonerpic maleate in patients with stroke. The lack of a biomarker to evaluate functional recovery in stroke patients hampers optimization of rehabilitation methods, and imaging with $\left[{ }^{11} \mathrm{C}\right] \mathrm{K}-2$ will provide a biological basis of functional recovery based on synaptic physiology of stroke patients who undergo rehabilitation in combination with edonerpic maleate (Table 1).

\section{Future perspectives}

We are currently conducting clinical $\left[{ }^{11} \mathrm{C}\right] \mathrm{K}-2$ PET studies to measure AMPARs in the brain among patients with various psychiatric disorders, including schizophrenia, depression, bipolar disorder, 
A<smiles>CN(CCSc1cc(F)c(OCC(N)=O)cc1F)S(=O)(=O)c1cccc(C(F)(F)F)c1</smiles>
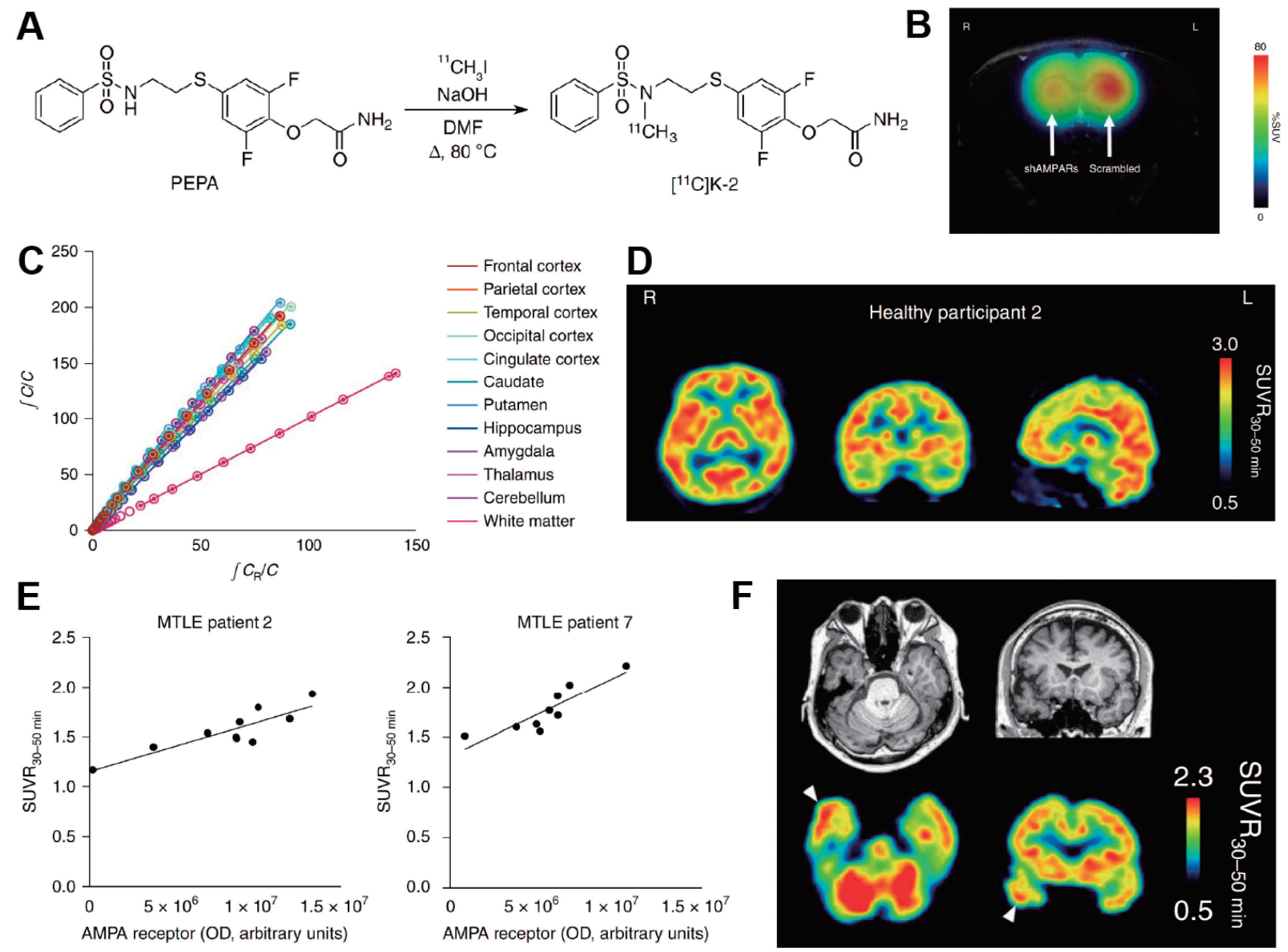

Fig. 4. The preclinical and clinical characteristics of $\left[{ }^{11} \mathrm{C}\right] \mathrm{K}-2$. (A) $\left[{ }^{11} \mathrm{C}\right] \mathrm{K}-2$ is synthesized by addition of ${ }^{11} \mathrm{CH}_{3} \mathrm{I}$ to the sulfonamide of PEPA. (B) Summation image of $\left[{ }^{11} \mathrm{C}\right] \mathrm{K}-2$ over the $20-40$ min after $\left[{ }^{11} \mathrm{C}\right] \mathrm{K}-2$ injection in an shRNA-injected rat showing that $\left[{ }^{11} \mathrm{C}\right] \mathrm{K}-2$ decreased in right striatum (shRNA targeted to AMPAR injected side) compared with left striatum (scrambled construct injected side). (C) LGA plot showing the ratio between the integrated tissue TAC in the reference region (white matter; $C_{\mathrm{R}}$ ) and a tissue TAC $(C)$ ( $x$ axis) plotted against the ratio of integrated $C$ with $C$ itself ( $y$ axis). A representative LGA plot is presented. The gradient was computed between 36 and $116 \mathrm{~min}$ after administration of the radiotracer. This result presents a good linear relationship observed in the graphical plots, indicating reversible binding kinetics for $\left[{ }^{11} \mathrm{C}\right] \mathrm{K}-2$. (D) Representative orthogonal parametric PET images of averaged standardized uptake value ratio (SUVR) using white matter as a reference during $30-50 \mathrm{~min}\left(\mathrm{SUVR}_{30-50 \mathrm{~min}}\right)$ after $\left[{ }^{11} \mathrm{C}\right] \mathrm{K}-2$ injection. (E) Correlations between $\mathrm{SUVR}_{30-50 \min }$ for $\left[{ }^{11} \mathrm{C}\right] \mathrm{K}-2$ and the biochemical protein amount of AMPARs (OD) in multiple brain regions from patient 2 (left) and patient 7 (right) with mesial temporal lobe epilepsy (MTLE). These results exhibit a prominent strong significant positive correlation between the protein amount of AMPAR and $\mathrm{SUVR}_{30-50 \min }$, demonstrating that $\mathrm{SUVR}_{30-50 \mathrm{~min}}$ (with white matter as a reference region) reflects the regional abundance of AMPARs. (F) SUVR $30-50$ min images of $\left[{ }^{11} \mathrm{C}\right] \mathrm{K}-2$ and corresponding MRI images were obtained from a patient with MTLE. White arrowheads indicate the epileptogenic focus. This derives from Ref. 147.

and autism and neurological disorders such as dementia and epilepsy (Table 1). This will provide us with biological information on these disorders based on synaptic physiology, which will lead to recategorization of neuropsychiatric disorders according to the distribution of AMPAR and the development of a novel molecular disease concept, "AMPAR disorders" (Fig. 5). This approach will not only provide a brand-new diagnostic system but also enable choice of appropriate treatment options (e.g., AMPAR agonist, AMPAR antagonist, focal stimulation) for the morbid conditions based on the distribution of AMPARs (Fig. 5). Moreover, this diagnostic system will be able to delineate a more homogenous group of patients. Although many clinical trials of psychotropic drugs have failed due to the heterogeneity of the psychiatric patients included, the use of $\left[{ }^{11} \mathrm{C}\right] \mathrm{K}-2$ as a companion 
Table 1. Clinical trials and studies with $\left[{ }^{11} \mathrm{C}\right] \mathrm{K}-2$

\section{Trial title}

Clinical trial to evaluate the efficacy and safety of $\left[{ }^{11} \mathrm{C}\right] \mathrm{K}-2$ in healthy volunteers The clinical trial to evaluate the efficacy of $\left[{ }^{11} \mathrm{C}\right] \mathrm{K}-2$ in refractory epilepsy patients undergoing anterior temporal lobectomy

The clinical pilot study to examine the distribution of $\left[{ }^{11} \mathrm{C}\right] \mathrm{K}-2$ in depression,

bipolar disease, schizophrenia, addiction, ASD, epilepsy, and FTD patients in order to develop a novel diagnostic method in cross-sectional way toward these diseases Clinical trial to examine the effective dose and safety of $\left[{ }^{11} \mathrm{C}\right] \mathrm{K}-2$ synthesized using a dedicated machine in healthy male volunteers

The exploratory clinical trial to evaluate the efficacy of $\left[{ }^{11} \mathrm{C}\right] \mathrm{K}-2$ in stroke patients under rehabilitation

Clinical trial to examine the densities of AMPA receptors in epilepsy patients with $\left[{ }^{11} \mathrm{C}\right] \mathrm{K}-2$

Clinical trial to examine the effectiveness of AMPA-PET to identify an

epileptogenic focus in refractory epilepsy patients

Investigator-initiated clinical trial to evaluate the efficacy of AMPA-PET in

functional recovery process by rehabilitation for subjects registered in the clinical phase II trial of T-817MA (T817MAJP201R trial)

The relationship of AMPA receptor density with presence or absence of subsequent onset in high-risk cases of psychosis: A longitudinal PET study using $\left[{ }^{11} \mathrm{C}\right] \mathrm{K}-2$

The relationship of AMPA receptor density in patients with autism spectrum

disorder: A transversal PET study using $\left[{ }^{11} \mathrm{C} \mid \mathrm{K}-2\right.$

The relationship of AMPA receptor density in patients with depression and bipolar disorder: A transversal PET study using $\left[{ }^{11} \mathrm{C}\right] \mathrm{K}-2$

The relationship of AMPA receptor density in patients with schizophrenia: A transversal PET study using $\left[{ }^{11} \mathrm{C}\right] \mathrm{K}-2$

A pilot study to validate the estimate of accuracy between standard uptake value ratio and non displaceable binding potential obtained from $\left[{ }^{11} \mathrm{C}\right] \mathrm{K}-2$ PET imaging in major cognitive disorders

A transversal PET study using $\left[{ }^{11} \mathrm{C}\right] \mathrm{K}-2$ to investigate age-and-sex-related changes in AMPA receptor density in healthy volunteers
Trial number Type of disease

UMIN000020975 Healthy volunteers

UMIN000025090 Refractory epilepsy patients

UMIN000025132 Mental disease/

Healthy volunteers

UMIN000026357 Healthy volunteers

UMIN000029952 Stroke

UMIN000031624 Epilepsy patients

JapicCTI-194576 Refractory epilepsy patients

JapicCTI-194711 Stroke

jRCTs031190151 ARMS

jRCTs031190149 ASD

jRCTs031190150 Depression/Bipolar

jRCTs031190197 Schizophrenia

jRCTs031190262 Major cognitive disorders

jRCTs031200083 Healthy volunteers

\author{
(n)
}

diagnostic could dramatically improve the success rate of future clinical trials because their target samples will be homogenous.

Moreover, the biological evidence obtained at the bedside will be used to classify, optimize, or produce appropriate and valid animal disease models at the bench in accordance with synaptic phenotypes in patients, leading to the elucidation of biological mechanisms of neuropsychiatric disorders such as dissection of the circuits responsible for pathogenesis. These findings at the bench will enable the development of therapeutics with novel mechanisms of action, which in turn will bring therapeutic benefits to patients at the bedside.

In addition to drugs directly acting on AMPARs, edonerpic maleate, which modulates trafficking of AMPARs is also a promising therapeu- tic compound. This compound enhances functional recovery after brain damage, such as stroke, in a unique manner that is rehabilitative training dependent. This therapeutic scheme may be applicable to other motor function disorder (e.g., Parkinson's disease, spinal cord injury). Furthermore, edonerpic maleate may also be effective for psychiatric disorders in combination with cognitive behavioral therapy.

In summary, AMPAR has enormous potential as a translational target. Rigorous scientific approaches will open the door of translational medicine of AMPARs, which is expected to greatly increase the quality of life of patients suffering from neuropsychiatric disorders.

\section{Acknowledgement}

This work was supported by Special Coordina- 


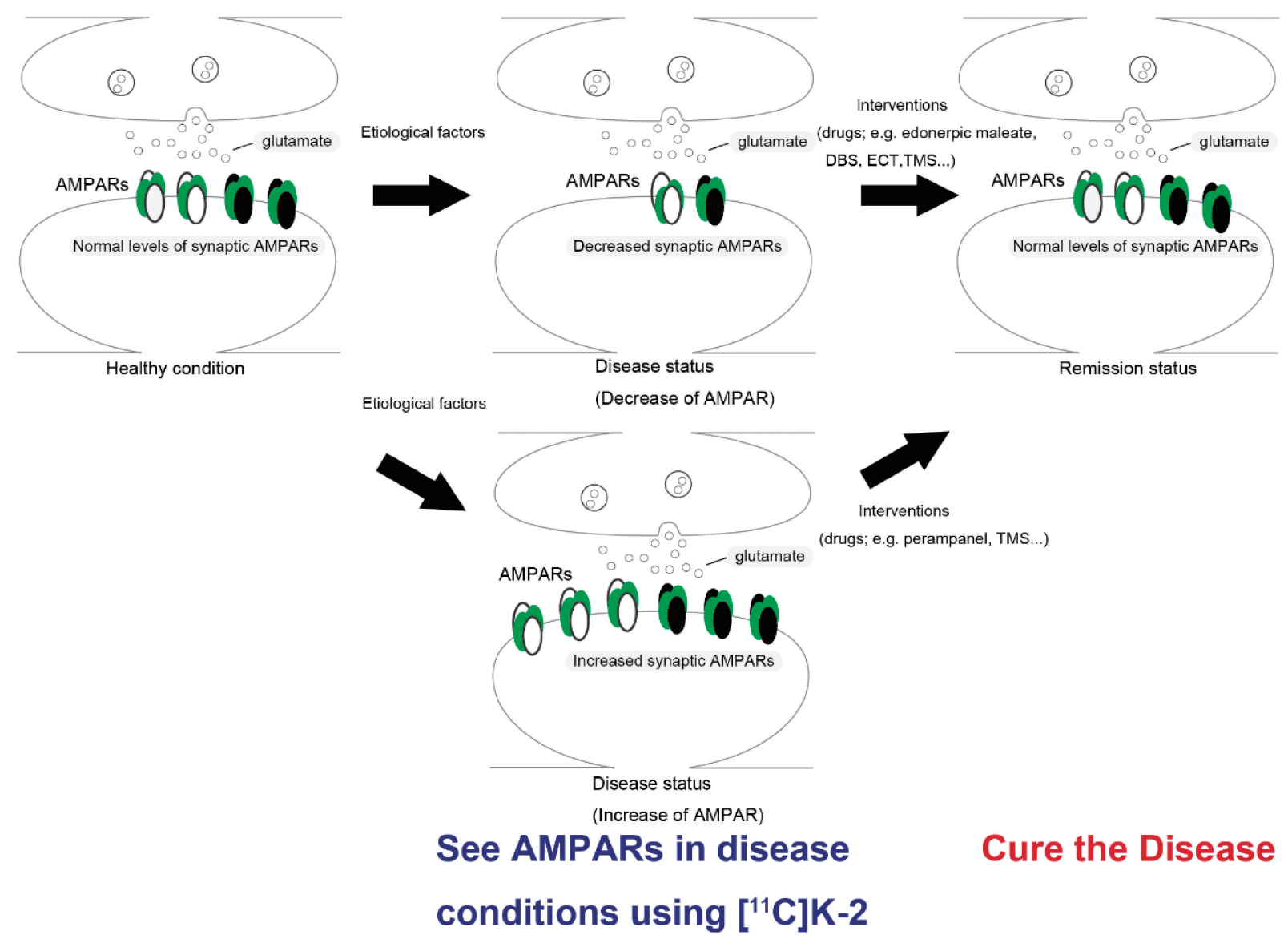

Fig. 5. Diagnosis and therapeutic scheme for AMPAR-related diseases. The levels of synaptic AMPAR can be altered under disease conditions. This synaptic disease status can be monitored with AMPA-PET imaging ([11 C]K-2): "See the disease". Effective therapeutic interventions such as drugs and mechanical manipulations can restore the levels of synaptic AMPAR to a normal level, thereby reaching remission status. DBS: deep brain stimulation, ECT: electroconvulsive therapy, TMS: transcranial magnetic stimulation.

tion Funds for Promoting Science and Technology (T.T.), AMED under Grant Number JP19dm0107124 (T.T.), JP18dm0207023 (T.T.), JP19lm0203007 (T.T.), Takeda Science Foundation (T.T.), The Uehara Memorial Foundation (T.T.), and KAKENHI under grant number $20 \mathrm{H} 00549$ (T.T.).

\section{References}

1) Sheng, M. and Kim, E. (2011) The postsynaptic organization of synapses. Cold Spring Harb. Perspect. Biol. 3, a005678.

2) Obi-Nagata, K., Temma, Y. and Hayashi-Takagi, A. (2019) Synaptic functions and their disruption in schizophrenia: From clinical evidence to synaptic optogenetics in an animal model. Proc. Jpn. Acad. Ser. B 95, 179-197.

3) Malinow, R. and Malenka, R.C. (2002) AMPA receptor trafficking and synaptic plasticity. Annu.
Rev. Neurosci. 25, 103-126.

4) Diering, G.H. and Huganir, R.L. (2018) The AMPA receptor code of synaptic plasticity. Neuron 100, 314-329.

5) Hollmann, M. and Heinemann, S. (1994) Cloned glutamate receptors. Annu. Rev. Neurosci. 17, 31-108.

6) Shepherd, J.D. and Huganir, R.L. (2007) The cell biology of synaptic plasticity: AMPA receptor trafficking. Annu. Rev. Cell Dev. Biol. 23, 613643.

7) Abe, H., Jitsuki, S., Nakajima, W., Murata, Y., Jitsuki-Takahashi, A., Katsuno, Y. et al. (2018) CRMP2-binding compound, edonerpic maleate, accelerates motor function recovery from brain damage. Science 360, 50-57.

8) Schwenk, J., Baehrens, D., Haupt, A., Bildl, W., Boudkkazi, S., Roeper, J. et al. (2014) Regional diversity and developmental dynamics of the AMPA-receptor proteome in the mammalian brain. Neuron 84, 41-54. 
9) Yan, D., Yamasaki, M., Straub, C., Watanabe, M. and Tomita, S. (2013) Homeostatic control of synaptic transmission by distinct glutamate receptors. Neuron 78, 687-699.

10) Matsuda, K., Miura, E., Miyazaki, T., Kakegawa, W., Emi, K., Narumi, S. et al. (2010) Cbln1 is a ligand for an orphan glutamate receptor $\delta 2$, a bidirectional synapse organizer. Science 328, 363368.

11) Bliss, T.V. and Lomo, T. (1973) Long-lasting potentiation of synaptic transmission in the dentate area of the anaesthetized rabbit following stimulation of the perforant path. J. Physiol. 232, $331-356$.

12) Bliss, T.V. and Gardner-Medwin, A.R. (1973) Longlasting potentiation of synaptic transmission in the dentate area of the unanaestetized rabbit following stimulation of the perforant path. J. Physiol. 232, 357-374.

13) Ito, M. and Kano, M. (1982) Long-lasting depression of parallel fiber-Purkinje cell transmission induced by conjunctive stimulation of parallel fibers and climbing fibers in the cerebellar cortex. Neurosci. Lett. 33, 253-258.

14) Ito, M., Sakurai, M. and Tongroach, P. (1982) Climbing fibre induced depression of both mossy fibre responsiveness and glutamate sensitivity of cerebellar Purkinje cells. J. Physiol. 324, 113-134.

15) Ito, M. (2006) Cerebellar circuitry as a neuronal machine. Prog. Neurobiol. 78, 272-303.

16) Derkach, V.A., Oh, M.C., Guire, E.S. and Soderling, T.R. (2007) Regulatory mechanisms of AMPA receptors in synaptic plasticity. Nat. Rev. Neurosci. 8, 101-113.

17) Bredt, D.S. and Nicoll, R.A. (2003) AMPA receptor trafficking at excitatory synapses. Neuron $\mathbf{4 0}$ 361-379.

18) Huganir, R.L. and Nicoll, R.A. (2013) AMPARs and synaptic plasticity: The last 25 years. Neuron $\mathbf{8 0}$, 704-717.

19) Kessels, H.W. and Malinow, R. (2009) Synaptic AMPA receptor plasticity and behavior. Neuron 61, 340-350.

20) Shi, S.H., Hayashi, Y., Petralia, R.S., Zaman, S.H., Wenthold, R.J., Svoboda, K. et al. (1999) Rapid spine delivery and redistribution of AMPA receptors after synaptic NMDA receptor activation. Science 284, 1811-1816.

21) Hayashi, Y., Shi, S.H., Esteban, J.A., Piccini, A., Poncer, J.C. and Malinow, R. (2000) Driving AMPA receptors into synapses by LTP and CaMKII: Requirement for GluR1 and PDZ domain interaction. Science 287, 2262-2267.

22) Shi, S., Hayashi, Y., Esteban, J.A. and Malinow, R. (2001) Subunit-specific rules governing AMPA receptor trafficking to synapses in hippocampal pyramidal neurons. Cell 105, 331-343.

23) Wenthold, R.J., Petralia, R.S., Blahos, J., II and Niedzielski, A.S. (1996) Evidence for multiple AMPA receptor complexes in hippocampal CA1/ CA2 neurons. J. Neurosci. 16, 1982-1989.

24) Henley, J.M. and Wilkinson, K.A. (2016) Synaptic
AMPA receptor composition in development, plasticity and disease. Nat. Rev. Neurosci. 17, 337-350.

25) Plant, K., Pelkey, K.A., Bortolotto, Z.A., Morita, D., Terashima, A., McBain, C.J. et al. (2006) Transient incorporation of native GluR2-lacking AMPA receptors during hippocampal long-term potentiation. Nat. Neurosci. 9, 602-604.

26) Takahashi, T., Svoboda, K. and Malinow, R. (2003) Experience strengthening transmission by driving AMPA receptors into synapses. Science 299, 1585-1588.

27) Rumpel, S., LeDoux, J., Zador, A. and Malinow, R. (2005) Postsynaptic receptor trafficking underlying a form of associative learning. Science $\mathbf{3 0 8}$, 83-88.

28) Whitlock, J.R., Heynen, A.J., Shuler, M.G. and Bear, M.F. (2006) Learning induces long-term potentiation in the hippocampus. Science 313, 1093-1097.

29) Mitsushima, D., Ishihara, K., Sano, A., Kessels, H.W. and Takahashi, T. (2011) Contextual learning requires synaptic AMPA receptor delivery in the hippocampus. Proc. Natl. Acad. Sci. U.S.A. 108, 12503-12508.

30) Mitsushima, D., Sano, A. and Takahashi, T. (2013) A cholinergic trigger drives learning-induced plasticity at hippocampal synapses. Nat. Commun. 4, 2760 .

31) Takemoto, K., Iwanari, H., Tada, H., Suyama, K., Sano, A., Nagai, T. et al. (2017) Optical inactivation of synaptic AMPA receptors erases fear memory. Nat. Biotechnol. 35, 38-47.

32) World Health Organization (1992) International Statistical Classification of Diseases and Related Health Problems (10th revision). World Health Organization, Geneva.

33) American Psychiatric Association (1994) Diagnostic and Statistical Manual of Mental Disorders, 4th ed. American Psychiatric Association, Washington, D.C

34) Ghaemi, S.N., Boiman, E.E. and Goodwin, F.K. (2000) Diagnosing bipolar disorder and the effect of antidepressants: A naturalistic study. J. Clin. Psychiatry 61, 804-808.

35) Hirschfeld, R.M., Lewis, L. and Vornik, L.A. (2003) Perceptions and impact of bipolar disorder: How far have we really come? Results of the national depressive and manic-depressive association 2000 survey of individuals with bipolar disorder. J. Clin. Psychiatry 64, 161-174.

36) Shi, L., Thiebaud, P. and McCombs, J.S. (2004) The impact of unrecognized bipolar disorders for patients treated for depression with antidepressants in the fee-for-services California Medicaid (Medi-Cal) program. J. Affect. Disord. 82, 373383.

37) Kapur, S. and Mamo, D. (2003) Half a century of antipsychotics and still a central role for dopamine $\mathrm{D}_{2}$ receptors. Prog. Neuropsychopharmacol. Biol. Psychiatry 27, 1081-1090.

38) Rush, A.J., Trivedi, M.H., Wisniewski, S.R., 
Nierenberg, A.A., Stewart, J.W., Warden, D. et al. (2006) Acute and longer-term outcomes in depressed outpatients requiring one or several treatment steps: A STAR*D report. Am. J. Psychiatry 163, 1905-1917.

39) Farooq, S., Agid, O., Foussias, G. and Remington, G. (2013) Using treatment response to subtype schizophrenia: Proposal for a new paradigm in classification. Schizophr. Bull. 39, 1169-1172.

40) Kambeitz, J.P. and Howes, O.D. (2015) The serotonin transporter in depression: Meta-analysis of in vivo and post mortem findings and implications for understanding and treating depression. J. Affect. Disord. 186, 358-366.

41) Wang, L., Zhou, C., Zhu, D., Wang, X., Fang, L., Zhong, J. et al. (2016) Serotonin-1A receptor alterations in depression: A meta-analysis of molecular imaging studies. BMC Psychiatry 16, 319.

42) Maletic, V., Eramo, A., Gwin, K., Offord, S.J. and Duffy, R.A. (2017) The role of norepinephrine and its $\alpha$-adrenergic receptors in the pathophysiology and treatment of major depressive disorder and schizophrenia: A systematic review. Front. Psychiatry $\mathbf{8}, 42$.

43) Moriguchi, S., Yamada, M., Takano, H., Nagashima, T., Takahata, K., Yokokawa, K. et al. (2017) Norepinephrine transporter in major depressive disorder: A PET study. Am. J. Psychiatry $\mathbf{1 7 4}, 36-41$.

44) Arnone, D., Job, D., Selvaraj, S., Abe, O., Amico, F., Cheng, Y. et al. (2016) Computational metaanalysis of statistical parametric maps in major depression. Hum. Brain Mapp. 37, 1393-1404.

45) Chen, G., Guo, Y., Zhu, H., Kuang, W., Bi, F., Ai, $\mathrm{H}$. et al. (2017) Intrinsic disruption of white matter microarchitecture in first-episode, drugnaive major depressive disorder: A voxel-based meta-analysis of diffusion tensor imaging. Prog. Neuropsychopharmacol. Biol. Psychiatry 76, 179-187.

46) Moriguchi, S., Takamiya, A., Noda, Y., Horita, N., Wada, M., Tsugawa, S. et al. (2019) Glutamatergic neurometabolite levels in major depressive disorder: A systematic review and meta-analysis of proton magnetic resonance spectroscopy studies. Mol. Psychiatry 24, 952-964.

47) Howes, O.D., Kambeitz, J., Kim, E., Stahl, D., Slifstein, M., Abi-Dargham, A. et al. (2012) The nature of dopamine dysfunction in schizophrenia and what this means for treatment. Arch. Gen. Psychiatry 69, 776-786.

48) Kapur, S., Zipursky, R.B. and Remington, G. (1999) Clinical and theoretical implications of $5-\mathrm{HT}_{2}$ and $\mathrm{D}_{2}$ receptor occupancy of clozapine, risperidone, and olanzapine in schizophrenia. Am. J. Psychiatry 156, 286-293.

49) Krystal, J.H., Karper, L.P., Seibyl, J.P., Freeman, G.K., Delaney, R., Bremner, J.D. et al. (1994) Subanesthetic effects of the noncompetitive NMDA antagonist, ketamine, in humans. Psychotomimetic, perceptual, cognitive, and neuroendo- crine responses. Arch. Gen. Psychiatry 51, 199214.

50) Allen, R.M. and Young, S.J. (1978) Phencyclidineinduced psychosis. Am. J. Psychiatry 135, 10811084.

51) Brugger, S.P. and Howes, O.D. (2017) Heterogeneity and homogeneity of regional brain structure in schizophrenia: A meta-analysis. JAMA Psychiatry $\mathbf{7 4}, 1104-1111$.

52) van Erp, T.G., Hibar, D.P., Rasmussen, J.M., Glahn, D.C., Pearlson, G.D., Andreassen, O.A. et al. (2016) Subcortical brain volume abnormalities in 2028 individuals with schizophrenia and 2540 healthy controls via the ENIGMA consortium. Mol. Psychiatry 21, 547-553.

53) Merritt, K., Egerton, A., Kempton, M.J., Taylor, M.J. and McGuire, P.K. (2016) Nature of glutamate alterations in schizophrenia: A metaanalysis of proton magnetic resonance spectroscopy studies. JAMA Psychiatry 73, 665-674.

54) Egerton, A., Brugger, S., Raffin, M., Barker, G.J., Lythgoe, D.J., McGuire, P.K. et al. (2012) Anterior cingulate glutamate levels related to clinical status following treatment in first-episode schizophrenia. Neuropsychopharmacology 37, 2515-2521.

55) Egerton, A., Broberg, B.V., Van Haren, N., Merritt, K., Barker, G.J., Lythgoe, D.J. et al. (2018) Response to initial antipsychotic treatment in first episode psychosis is related to anterior cingulate glutamate levels: A multicentre ${ }^{1} \mathrm{H}-\mathrm{MRS}$ study (OPTiMiSE). Mol. Psychiatry 23, 2145-2155.

56) Demjaha, A., Egerton, A., Murray, R.M., Kapur, S., Howes, O.D., Stone, J.M. et al. (2014) Antipsychotic treatment resistance in schizophrenia associated with elevated glutamate levels but normal dopamine function. Biol. Psychiatry 75, e11-e13.

57) Mouchlianitis, E., Bloomfield, M.A., Law, V., Beck, K., Selvaraj, S., Rasquinha, N. et al. (2016) Treatment-resistant schizophrenia patients show elevated anterior cingulate cortex glutamate compared to treatment-responsive. Schizophr. Bull. 42, 744-752.

58) Zhu, J., Zhuo, C., Qin, W., Xu, Y., Xu, L., Liu, X. et al. (2015) Altered resting-state cerebral blood flow and its connectivity in schizophrenia. J. Psychiatr. Res. 63, 28-35.

59) Greer, P.L., Hanayama, R., Bloodgood, B.L., Mardinly, A.R., Lipton, D.M., Flavell, S.W. et al. (2010) The Angelman Syndrome protein Ube3A regulates synapse development by ubiquitinating Arc. Cell 140, 704-716.

60) Miyazaki, T., Takase, K., Nakajima, W., Tada, H., Ohya, D., Sano, A. et al. (2012) Disrupted cortical function underlies behavior dysfunction due to social isolation. J. Clin. Invest. 122, 2690-2701.

61) Udagawa, T., Fujioka, Y., Tanaka, M., Honda, D., Yokoi, S., Riku, Y. et al. (2015) FUS regulates AMPA receptor function and FTLD/ALS-associated behaviour via GluA1 mRNA stabilization. Nat. Commun. 6, 7098.

62) Zanos, P., Moaddel, R., Morris, P.J., Georgiou, P., 
Fischell, J., Elmer, G.I. et al. (2016) NMDAR inhibition-independent antidepressant actions of ketamine metabolites. Nature 533, 481-486.

63) Nagahama, K., Sakoori, K., Watanabe, T., Kishi, Y., Kawaji, K., Koebis, M. et al. (2020) Setd1a Insufficiency in mice attenuates excitatory synaptic function and recapitulates schizophrenia-related behavioral abnormalities. Cell Rep. 32, 108126.

64) Soto, D., Altafaj, X., Sindreu, C. and Bayes, A. (2014) Glutamate receptor mutations in psychiatric and neurodevelopmental disorders. Commun. Integr. Biol. 7, e27887.

65) Chiyonobu, T., Hayashi, S., Kobayashi, K., Morimoto, M., Miyanomae, Y., Nishimura, A. et al. (2007) Partial tandem duplication of GRIA3 in a male with mental retardation. Am. J. Med. Genet. A 143A, 1448-1455.

66) Wu, Y., Arai, A.C., Rumbaugh, G., Srivastava, A.K., Turner, G., Hayashi, T. et al. (2007) Mutations in ionotropic AMPA receptor 3 alter channel properties and are associated with moderate cognitive impairment in humans. Proc. Natl. Acad. Sci. U.S.A. 104, 18163-18168.

67) Guilmatre, A., Dubourg, C., Mosca, A.L., Legallic, S., Goldenberg, A., Drouin-Garraud, V. et al. (2009) Recurrent rearrangements in synaptic and neurodevelopmental genes and shared biologic pathways in schizophrenia, autism, and mental retardation. Arch. Gen. Psychiatry 66, 947-956.

68) Ueno, F., Suzuki, T., Nakajima, S., Matsushita, S., Mimura, M., Miyazaki, T. et al. (2019) Alteration in AMPA receptor subunit expression and receptor binding among patients with addictive disorders: A systematic review of human postmortem studies. Neuropsychopharmacol. Rep. 39, 148155.

69) Feigin, V.L., Nichols, E., Alam, T., Bannick, M.S., Beghi, E., Blake, N. et al. (2019) Global, regional, and national burden of neurological disorders, 1990-2016: A systematic analysis for the Global Burden of Disease Study 2016. Lancet Neurol. 18, 459-480.

70) Maling, H.M. and Acheson, G.H. (1946) Righting and other postural activity in low-decerebrate and in spinal cats after d-amphetamine. J. Neurophysiol. 9, 379-386.

71) Cohen, H.P., Waltz, A.G. and Jacobson, R.L. (1975) Catecholamine content of cerebral tissue after occlusion or manipulation of middle cerebral artery in cats. J. Neurosurg. 43, 32-36.

72) Feeney, D.M., Gonzalez, A. and Law, W.A. (1982) Amphetamine, haloperidol, and experience interact to affect rate of recovery after motor cortex injury. Science 217, 855-857.

73) Adkins, D.L. and Jones, T.A. (2005) D-Amphetamine enhances skilled reaching after ischemic cortical lesions in rats. Neurosci. Lett. 380, 214218.

74) Sonde, L., Nordstrom, M., Nilsson, C.G., Lokk, J. and Viitanen, M. (2001) A double-blind placebocontrolled study of the effects of amphetamine and physiotherapy after stroke. Cerebrovasc. Dis. 12, 253-257.

75) Goldstein, L.B., Lennihan, L., Rabadi, M.J., Good, D.C., Reding, M.J., Dromerick, A.W. et al. (2018) Effect of dextroamphetamine on poststroke motor recovery: A randomized clinical trial. JAMA Neurol. 75, 1494-1501.

76) Stroemer, R.P., Kent, T.A. and Hulsebosch, C.E. (1998) Enhanced neocortical neural sprouting, synaptogenesis, and behavioral recovery with damphetamine therapy after neocortical infarction in rats. Int. J. Stroke 29, 2381-2395.

77) Dunwiddie, T.V., Roberson, N.L. and Worth, T. (1982) Modulation of long-term potentiation: Effects of adrenergic and neuroleptic drugs. Pharmacol. Biochem. Behav. 17, 1257-1264.

78) Abe, H., Jitsuki, S. and Takahashi, T. (2019) Pharmacological enhancement of stroke rehabilitation. Int. J. Stroke 50, 3323-3329.

79) Dam, M., Tonin, P., De Boni, A., Pizzolato, G., Casson, S., Ermani, M. et al. (1996) Effects of fluoxetine and maprotiline on functional recovery in poststroke hemiplegic patients undergoing rehabilitation therapy. Int. J. Stroke 27, 12111214.

80) Pariente, J., Loubinoux, I., Carel, C., Albucher, J.F., Leger, A., Manelfe, C. et al. (2001) Fluoxetine modulates motor performance and cerebral activation of patients recovering from stroke. Ann. Neurol. 50, 718-729.

81) Maya Vetencourt, J.F., Sale, A., Viegi, A., Baroncelli, L., De Pasquale, R., O'Leary, O.F. et al. (2008) The antidepressant fluoxetine restores plasticity in the adult visual cortex. Science 320, 385-388.

82) Chollet, F., Tardy, J., Albucher, J.-F., Thalamas, C., Berard, E., Lamy, C. et al. (2011) Fluoxetine for motor recovery after acute ischaemic stroke (FLAME): A randomised placebo-controlled trial. Lancet Neurol. 10, 123-130.

83) Dennis, M., Mead, G., Forbes, J., Graham, C., Hackett, M., Hankey, G.J. et al. (2019) Effects of fluoxetine on functional outcomes after acute stroke (FOCUS): A pragmatic, double-blind, randomised, controlled trial. Lancet 393, 265274 .

84) Mead, G.E., Legg, L., Tilney, R., Hsieh, C.F., Wu, S., Lundström, E. et al. (2020) Fluoxetine for stroke recovery: Meta-analysis of randomized controlled trials. Int. J. Stroke 15, 365-376.

85) Fisher, R.S., Cross, J.H., French, J.A., Higurashi, N., Hirsch, E., Jansen, F.E. et al. (2017) Operational classification of seizure types by the International League Against Epilepsy: Position Paper of the ILAE Commission for Classification and Terminology. Epilepsia 58, 522-530.

86) Singh, A. and Trevick, S. (2016) The Epidemiology of Global Epilepsy. Neurol. Clin. 34, 837-847.

87) Shorvon, S. (1988) The course of untreated epilepsy. BMJ 297, 1405.

88) French, J.A. and Gazzola, D.M. (2011) New generation antiepileptic drugs: What do they offer 
in terms of improved tolerability and safety? Ther. Adv. Drug Saf. 2, 141-158.

89) Engel, J., Jr., McDermott, M.P., Wiebe, S., Langfitt, J.T., Stern, J.M., Dewar, S. et al. (2012) Early surgical therapy for drug-resistant temporal lobe epilepsy: A randomized trial. JAMA 307, 922-930.

90) Wiebe, S., Blume, W.T., Girvin, J.P. and Eliasziw, M. (2001) A randomized, controlled trial of surgery for temporal-lobe epilepsy. N. Engl. J. Med. 345, 311-318.

91) Aghaei-Lasboo, A. and Fisher, R.S. (2016) Methods for measuring seizure frequency and severity. Neurol. Clin. 34, 383-394.

92) Krishna, V., Sammartino, F. and Rezai, A. (2018) A review of the current therapies, challenges, and future directions of transcranial focused ultrasound technology: Advances in diagnosis and treatment. JAMA Neurol. 75, 246-254.

93) Zilles, K., Qu, M.S., Kohling, R. and Speckmann, E.J. (1999) Ionotropic glutamate and GABA receptors in human epileptic neocortical tissue: Quantitative in vitro receptor autoradiography. Neuroscience 94, 1051-1061.

94) Braak, H., Del Tredici, K., Rub, U., de Vos, R.A., Jansen Steur, E.N. and Braak, E. (2003) Staging of brain pathology related to sporadic Parkinson's disease. Neurobiol. Aging 24, 197-211.

95) Salat, D. and Tolosa, E. (2013) Levodopa in the treatment of Parkinson's disease: Current status and new developments. J. Parkinsons Dis. 3, 255269.

96) Fahn, S., Oakes, D., Shoulson, I., Kieburtz, K., Rudolph, A., Lang, A. et al. (2004) Levodopa and the progression of Parkinson's disease. N. Engl. J. Med. 351, 2498-2508.

97) Verschuur, C.V.M., Suwijn, S.R., Boel, J.A., Post, B., Bloem, B.R., van Hilten, J.J. et al. (2019) Randomized delayed-start trial of levodopa in Parkinson's disease. N. Engl. J. Med. 380, 315324.

98) Birks, J.S. and Harvey, R.J. (2018) Donepezil for dementia due to Alzheimer's disease. Cochrane Database Syst. Rev. 6, CD001190

99) Li, D.-D., Zhang, Y.-H., Zhang, W. and Zhao, P. (2019) Meta-analysis of randomized controlled trials on the efficacy and safety of donepezil, galantamine, rivastigmine, and memantine for the treatment of Alzheimer's disease. Front. Neurosci. 13, 472 .

100) Scheuner, D., Eckman, C., Jensen, M., Song, X., Citron, M., Suzuki, N. et al. (1996) Secreted amyloid $\beta$-protein similar to that in the senile plaques of Alzheimer's disease is increased in vivo by the presenilin 1 and 2 and APP mutations linked to familial Alzheimer's disease. Nat. Med. 2, 864-870.

101) De Strooper, B., Saftig, P., Craessaerts, K. Vanderstichele, H., Guhde, G., Annaert, W. et al. (1998) Deficiency of presenilin-1 inhibits the normal cleavage of amyloid precursor protein. Nature 391, 387-390.
102) Hardy, J. and Selkoe, D.J. (2002) The amyloid hypothesis of Alzheimer's disease: Progress and problems on the road to therapeutics. Science 297, 353-356.

103) Jack, C.R., Jr., Knopman, D.S., Jagust, W.J., Shaw, L.M., Aisen, P.S., Weiner, M.W. et al. (2010) Hypothetical model of dynamic biomarkers of the Alzheimer's pathological cascade. Lancet Neurol. 9, 119-128.

104) Schenk, D., Barbour, R., Dunn, W., Gordon, G., Grajeda, H., Guido, T. et al. (1999) Immunization with amyloid- $\beta$ attenuates Alzheimer-disease-like pathology in the PDAPP mouse. Nature 400, 173-177.

105) Sevigny, J., Chiao, P., Bussiere, T., Weinreb, P.H., Williams, L., Maier, M. et al. (2016) The antibody aducanumab reduces $\mathrm{A} \beta$ plaques in Alzheimer's disease. Nature 537, 50-56.

106) Doody, R.S., Thomas, R.G., Farlow, M., Iwatsubo, T., Vellas, B., Joffe, S. et al. (2014) Phase 3 trials of solanezumab for mild-to-moderate Alzheimer's disease. N. Engl. J. Med. 370, 311-321.

107) Lepeta, K., Lourenco, M.V., Schweitzer, B.C., Martino Adami, P.V., Banerjee, P., CatuaraSolarz, S. et al. (2016) Synaptopathies: Synaptic dysfunction in neurological disorders-A review from students to students. J. Neurochem. 138, 785-805.

108) Selkoe, D.J. (2002) Alzheimer's disease is a synaptic failure. Science 298, 789-791.

109) Terry, R.D., Masliah, E., Salmon, D.P., Butters, N., DeTeresa, R., Hill, R. et al. (1991) Physical basis of cognitive alterations in Alzheimer's disease: Synapse loss is the major correlate of cognitive impairment. Ann. Neurol. 30, 572-580.

110) DeKosky, S.T. and Scheff, S.W. (1990) Synapse loss in frontal cortex biopsies in Alzheimer's disease: Correlation with cognitive severity. Ann. Neurol. 27, 457-464.

111) Armstrong, D.M., Ikonomovic, M.D., Sheffield, R. and Wenthold, R.J. (1994) AMPA-selective glutamate receptor subtype immunoreactivity in the entorhinal cortex of non-demented elderly and patients with Alzheimer's disease. Brain Res. 639, 207-216.

112) Hsieh, H., Boehm, J., Sato, C., Iwatsubo, T., Tomita, T., Sisodia, S. et al. (2006) AMPAR removal underlies $\mathrm{A} \beta$-induced synaptic depression and dendritic spine loss. Neuron 52, 831-843.

113) Wei, W., Nguyen, L.N., Kessels, H.W., Hagiwara, H., Sisodia, S. and Malinow, R. (2010) Amyloid beta from axons and dendrites reduces local spine number and plasticity. Nat. Neurosci. 13, 190196.

114) Chapman, P.F., White, G.L., Jones, M.W., CooperBlacketer, D., Marshall, V.J., Irizarry, M. et al. (1999) Impaired synaptic plasticity and learning in aged amyloid precursor protein transgenic mice. Nat. Neurosci. 2, 271-276.

115) Vossel, K.A., Tartaglia, M.C., Nygaard, H.B., Zeman, A.Z. and Miller, B.L. (2017) Epileptic activity in Alzheimer's disease: Causes and clinical 
relevance. Lancet Neurol. 16, 311-322.

116) Lam, A.D., Deck, G., Goldman, A., Eskandar, E.N. Noebels, J. and Cole, A.J. (2017) Silent hippocampal seizures and spikes identified by foramen ovale electrodes in Alzheimer's disease. Nat. Med. 23, 678-680.

117) Busche, M.A., Chen, X., Henning, H.A., Reichwald, J., Staufenbiel, M., Sakmann, B. et al. (2012) Critical role of soluble amyloid- $\beta$ for early hippocampal hyperactivity in a mouse model of Alzheimer's disease. Proc. Natl. Acad. Sci. U.S.A. 109, 8740-8745.

118) Zhang, M.-Y., Zheng, C.-Y., Zou, M.-M., Zhu, J.-W., Zhang, Y., Wang, J. et al. (2014) Lamotrigine attenuates deficits in synaptic plasticity and accumulation of amyloid plaques in APP/PS1 transgenic mice. Neurobiol. Aging 35, 2713-2725.

119) Chang, E.H., Savage, M.J., Flood, D.G., Thomas, J.M., Levy, R.B., Mahadomrongkul, V. et al. (2006) AMPA receptor downscaling at the onset of Alzheimer's disease pathology in double knockin mice. Proc. Natl. Acad. Sci. U.S.A. 103, 34103415 .

120) Reinders, N.R., Pao, Y., Renner, M.C., da SilvaMatos, C.M., Lodder, T.R., Malinow, R. et al. (2016) Amyloid- $\beta$ effects on synapses and memory require AMPA receptor subunit GluA3. Proc. Natl. Acad. Sci. U.S.A. 113, E6526-E6534.

121) Guntupalli, S., Widagdo, J. and Anggono, V. (2016) Amyloid- $\beta$-induced dysregulation of AMPA receptor trafficking. Neural Plast. 2016, 3204519.

122) Nestler, E.J. and Hyman, S.E. (2010) Animal models of neuropsychiatric disorders. Nat. Neurosci. 13, 1161-1169.

123) Takao, K., Yamasaki, N. and Miyakawa, T. (2007) Impact of brain-behavior phenotypying of genetically-engineered mice on research of neuropsychiatric disorders. Neurosci. Res. 58, 124-132.

124) Rutkowski, T.P., Schroeder, J.P., Gafford, G.M., Warren, S.T., Weinshenker, D., Caspary, T. et al. (2017) Unraveling the genetic architecture of copy number variants associated with schizophrenia and other neuropsychiatric disorders. J. Neurosci. Res. 95, 1144-1160.

125) Barr, C.S., Newman, T.K., Becker, M.L., Parker, C.C., Champoux, M., Lesch, K.P. et al. (2003) The utility of the non-human primate; Model for studying gene by environment interactions in behavioral research. Genes Brain Behav. 2, 336340 .

126) Eltokhi, A., Kurpiers, B. and Pitzer, C. (2020) Behavioral tests assessing neuropsychiatric phenotypes in adolescent mice reveal strain- and sexspecific effects. Sci. Rep. 10, 11263.

127) Bale, T.L., Abel, T., Akil, H., Carlezon, W.A., Jr., Moghaddam, B., Nestler, E.J. et al. (2019) The critical importance of basic animal research for neuropsychiatric disorders. Neuropsychopharmacology 44, 1349-1353.

128) Lepeta, K., Lourenco, M.V., Schweitzer, B.C. Martino Adami, P.V., Banerjee, P., CatuaraSolarz, S. et al. (2016) Synaptopathies: Synaptic dysfunction in neurological disorders-A review from students to students. J. Neurochem. 138, 785-805.

129) Nudo, R.J. (2013) Recovery after brain injury: Mechanisms and principles. Front. Hum. Neurosci. 7,887 .

130) Jitsuki, S., Takemoto, K., Kawasaki, T., Tada, H., Takahashi, A., Becamel, C. et al. (2011) Serotonin mediates cross-modal reorganization of cortical circuits. Neuron 69, 780-792.

131) Nudo, R.J., Wise, B.M., SiFuentes, F. and Milliken, G.W. (1996) Neural substrates for the effects of rehabilitative training on motor recovery after ischemic infarct. Science 272, 1791-1794.

132) Goshima, Y., Nakamura, F., Strittmatter, P. and Strittmatter, S.M. (1995) Collapsin-induced growth cone collapse mediated by an intracellular protein related to UNC-33. Nature 376, 509-514.

133) Luo, Y., Raible, D. and Raper, J.A. (1993) Collapsin: A protein in brain that induces the collapse and paralysis of neuronal growth cones. Cell 75, 217-227.

134) Fiore, R. and Puschel, A.W. (2003) The function of semaphorins during nervous system development. Front. Biosci. 8, s484-s499.

135) Tran, T.S., Rubio, M.E., Clem, R.L., Johnson, D., Case, L., Tessier-Lavigne, M. et al. (2009) Secreted semaphorins control spine distribution and morphogenesis in the postnatal CNS. Nature 462, 1065-1069.

136) Duan, Y., Wang, S.H., Song, J., Mironova, Y., Ming, G.L., Kolodkin, A.L. et al. (2014) Semaphorin 5A inhibits synaptogenesis in early postnatal- and adult-born hippocampal dentate granule cells. eLife 3, e04390.

137) Jin, X., Sasamoto, K., Nagai, J., Yamazaki, Y., Saito, K., Goshima, Y. et al. (2016) Phosphorylation of CRMP2 by Cdk5 regulates dendritic spine development of cortical neuron in the mouse hippocampus. Neural Plast. 2016, 6790743.

138) Ziak, J., Weissova, R., Jerabkova, K., Janikova, M., Maimon, R., Petrasek, T. et al. (2020) CRMP2 mediates Sema3F-dependent axon pruning and dendritic spine remodeling. EMBO Rep. 21, e48512.

139) Zhang, Z., Zhang, J., Li, J., Zhang, J., Chen, L., Li, Y. et al. (2020) Ketamine regulates phosphorylation of CRMP2 to mediate dendritic spine plasticity. J. Mol. Neurosci. 70, 353-364.

140) Gu, J., Lee, C.W., Fan, Y., Komlos, D., Tang, X., Sun, C. et al. (2010) ADF/cofilin-mediated actin dynamics regulate AMPA receptor trafficking during synaptic plasticity. Nat. Neurosci. 13, $1208-1215$.

141) Fu, H., Chen, Z., Josephson, L., Li, Z. and Liang, S.H. (2019) Positron emission tomography (PET) ligand development for ionotropic glutamate receptors: Challenges and opportunities for radiotracer targeting $N$-methyl-D-aspartate (NMDA), $\alpha$-Amino-3-hydroxy-5-methyl-4-isoxazolepropionic Acid (AMPA) and Kainate Receptors. J. Med. Chem. 62, 403-419. 
142) Lee, K., Goodman, L., Fourie, C., Schenk, S., Leitch, B. and Montgomery, J.M. (2016) AMPA receptors as therapeutic targets for neurological disorders. Adv. Protein Chem. Struct. Biol. 103, 203-261.

143) Oi, N., Tokunaga, M., Suzuki, M., Nagai, Y., Nakatani, Y., Yamamoto, N. et al. (2015) Development of novel PET probes for central 2-amino3-(3-hydroxy-5-methyl-4-isoxazolyl)propionic acid receptors. J. Med. Chem. 58, 8444-8462.

144) Takahata, K., Kimura, Y., Seki, C., Tokunaga, M., Ichise, M., Kawamura, K. et al. (2017) A human PET study of $\left[{ }^{11} \mathrm{C} \mid \mathrm{HMS} 011\right.$, a potential radioligand for AMPA receptors. EJNMMI Res. 7, 63.

145) Gao, M., Kong, D., Clearfield, A. and Zheng, Q.H. (2006) Synthesis of carbon-11 and fluorine-18 labeled N-acetyl-1-aryl-6,7-dimethoxy-1,2,3,4-tetrahydroisoquinoline derivatives as new potential
PET AMPA receptor ligands. Bioorg. Med. Chem. Lett. 16, 2229-2233.

146) Årstad, E., Gitto, R., Chimirri, A., Caruso, R., Constanti, A., Turton, D. et al. (2006) Closing in on the AMPA receptor: Synthesis and evaluation of 2-acetyl-1-(4'-chlorophenyl)-6-methoxy-7$\left[{ }^{11} \mathrm{C}\right]$ methoxy-1,2,3,4-tetrahydroisoquinoline as a potential PET tracer. Bioorg. Med. Chem. 14, 4712-4717.

147) Miyazaki, T., Nakajima, W., Hatano, M., Shibata, Y., Kuroki, Y., Arisawa, T. et al. (2020) Visualization of AMPA receptors in living human brain with positron emission tomography. Nat. Med. 26, 281-288.

(Received Sep. 30, 2020; accepted Oct. 30, 2020)

\section{Profile}

Dr. Tomoyuki Miyazaki is an associate professor at the Department of Physiology, Yokohama City University School of Medicine in Kanagawa, Japan. His specialty is basic research in neuroscience and his clinical specialty is neuroanesthesia. He received his M.D. and Ph.D. at Yokohama City University School of Medicine in 2004 and 2012, respectively. After receiving his Ph.D. for his graduate research at the Department of Physiology (Dr. Takahashi's lab), he undertook a new project to develop a positron emission tomography (PET) tracer recognizing $\alpha$-amino-3-hydroxy-5-methyl-4-isoxazole propionic acid receptors (AMPARs) and finally succeeded in the synthesis of $\left[{ }^{11} \mathrm{C}\right] \mathrm{K}-2$ as the best PET tracer for AMPARs. Following preclinical evaluations, he has been performing a variety of clinical trials to examine the ability of $\left[{ }^{11} \mathrm{C}\right] \mathrm{K}-2$ to elucidate the

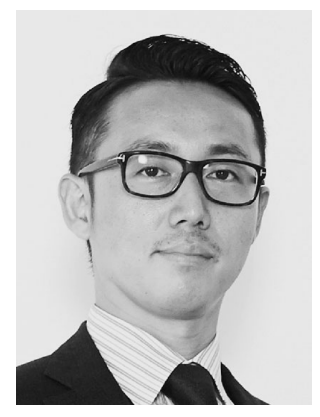
biological basis of neuropsychiatric disorders. He has received the President's award from Yokohama City University. He is a member of the working group on the nervous system for the Japanese Society of Anesthesiologists.

\section{Profile}

Dr. Hiroki Abe is an assistant professor at the Department of Physiology, Yokohama City University School of Medicine in Kanagawa, Japan. He received his M.D. at Yokohama City University in 2010. After training in Neurology as a resident physician, he started research on the rehabilitation accelerating agent edonerpic maleate, at the Department of Physiology from 2012 under the direction of Prof. Takuya Takahashi. Dr. Abe received his Ph.D. in 2019. The title of his doctoral thesis is "CRMP2-binding compound, edonerpic maleate accelerates motor function recovery from brain injury". He has also worked in clinical neurology at the National Center for Neurology and Psychiatry Hospital from 2017 to 2019. He is interested in the application of synapse physiology to clinical neurology, with a focus on excitatory glutamate AMPA

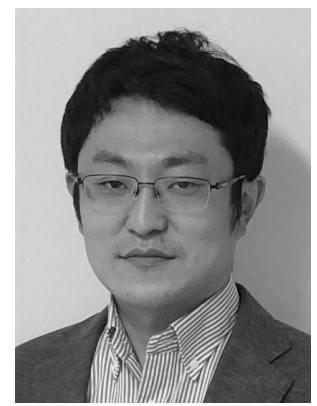
receptors. 


\section{Profile}

Dr. Hiroyuki Uchida is a senior lecturer at the Department of Neuropsychiatry, Keio University School of Medicine in Tokyo, Japan. He specializes in clinical psychopharmacology in schizophrenia. He received his M.D. and Ph.D. at Keio University School of Medicine in 1998 and 2006, respectively. Following his graduate training, he joined the Centre for Addiction and Mental Health, Toronto, Canada, and conducted brain imaging studies and pharmacokinetic work with a focus on aging in schizophrenia as a post-doctoral fellow. Dr. Uchida then returned to Keio University School of Medicine and became head of the Psychopharmacology Research Program. Dr. Uchida has been performing a series of clinical trials, brain imaging work, and pharmacokinetic studies focusing on the optimal antipsychotic treatment for schizo-

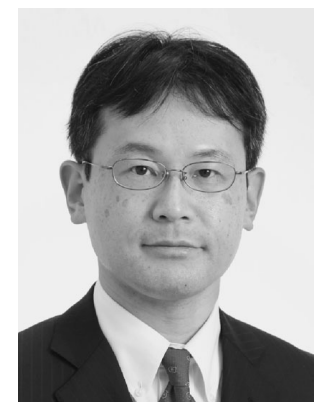
phrenia and mood disorders. Since his work on psychopharmacological treatment is of high clinical relevance, his work on these topics has been cited in numerous international treatment guidelines. He has received academic awards, including the Collegium Internationale Neuro-Psychopharmacologicum Poster Award, the American Association for Geriatric Psychiatry, Barry Lebowitz Early Career Scientist Award, and the Japanese Society of Neuropsychopharmacology, Academic Encouragement Award. He works as a co-editor for Pharmacopsychiatry, a field editor for Psychiatry and Clinical Neurosciences, an advisory editor for Psychopharmacology, and an international editorial board member for Journal of Clinical Psychopharmacology.

\section{Profile}

Dr. Takuya Takahashi was born in Tokyo in 1969. He is a professor at the Department of Physiology, Yokohama City University Graduate School of Medicine in Yokohama, Japan. He specializes in molecular, cellular, and synaptic physiology as well as human imaging. He received his M.D. at Keio University School of Medicine in 1995. He also received his Ph.D. from Yale University (CT, U.S.A.) in 2000. As a graduate student, he studied the molecular mechanisms of axon guidance. Through this research, he received the John Nicholas Spangler Award (an award for the best thesis). In 2000, he moved to the Cold Spring Harbor Laboratory (NY, U.S.A.) as a postdoctoral fellow, where he started research on experience-dependent synaptic AMPA receptor delivery. In 2006, he moved back to Japan (Yokohama City University) and started his own

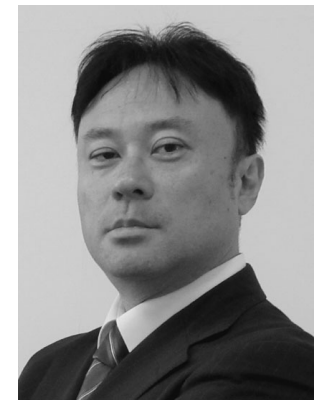
laboratory in his current position (Professor, Department of Physiology). While he continues to study experiencedependent synaptic AMPA receptor delivery in various behavioral and environmental conditions, he started research on translational medicine of AMPA receptors. He identified a small compound, edonerpic maleate, which accelerates motor function recovery from brain damage by facilitating synaptic AMPA receptor delivery, and developed the first positron emission tomography tracer, which is the first technology to visualize and quantify the density of AMPA receptors in the living human brain. He received the Kitasato Award in 2013 and the Nakaakira Tsukahara Memorial Award in 2019. 